\title{
Cu K-Edge EXAFS Characterisation of Copper(I) Arenethiolate Complexes in both the Solid and Liquid State: Detection of $\mathrm{Cu}-\mathrm{Cu}$ Coordination
}

\author{
Moniek Tromp, ${ }^{[a]}$ Jeroen A. van Bokhoven, ${ }^{[a]}$ Anne M. Arink, ${ }^{[b]}$ Johannes H. Bitter, ${ }^{[a]}$ \\ Gerard van Koten, ${ }^{[b]}$ and Diederik C. Koningsberger* ${ }^{[a]}$
}

\begin{abstract}
Herein we describe a structural characterisation with EXAFS of copper(I) arenethiolate complexes in both the solid and liquid state. Previously noted difficulties in the detection of the $\mathrm{Cu}-\mathrm{Cu}$ interaction have been attributed to anti-phase behaviour of different $\mathrm{Cu}-\mathrm{Cu}$ neighbour contributions. A data analysis procedure solely based on EXAFS parameters is presented which resolves these problems. A careful analysis of the individual coordination shells and the use of different $k$ weightings during the data analysis are shown to be an absolute necessity to
\end{abstract}

obtain reliable results. During $R$-space fitting, the difference file technique is used to separate, examine and compare the individual contributions. Using this technique their statistical significance and correctness can be determined. Anti-phase behaviour can be detected and accounted for in this way. An additional mixed organocopper aggregate $\left[\mathrm{Cu}_{4}(\mathrm{SAr})_{2}(\mathrm{Mes})_{2}\right]$ with different $\mathrm{Cu}$

Keywords: catalysts $\cdot$ copper $\cdot \mathrm{C}-\mathrm{C}$ coupling - EXAFS data analysis EXAFS spectroscopy sites is analysed, which proves the value of the analysis procedure described above. Moreover, this newly developed EXAFS data analysis procedure is applicable to any other EXAFS spectrum obtained. The structural analysis of these organocopper complexes with EXAFS provides information about their actual structure and dynamic behaviour in solution. The technique can now be used to obtain insights into the reactivity of these complexes and the way in which they form catalytic reaction intermediates.

\section{Introduction}

An important reaction in organic synthesis is the (selective) carbon-carbon bond formation for which organocuprates $\left[\mathrm{R}_{2} \mathrm{CuLi}\right],{ }^{[1-3]}\left[\mathrm{R}_{2} \mathrm{Cu}(\mathrm{CN}) \mathrm{Li}\right],{ }^{[4,5]}\left[\mathrm{R}_{2} \mathrm{Cu}(\mathrm{CN}) \mathrm{Li}_{2}\right]^{[6]}$ are most widely applied. ${ }^{[7-12]}$ In our ongoing studies in the field of organocopper and cuprate chemistry, we have synthesised well-defined heterocuprates derived from the aminoarenecopper species $\left(\mathrm{CuSC}_{6} \mathrm{H}_{4} \mathrm{CH}(\mathrm{Me}) \mathrm{NMe}_{2}-2\right)_{3} \quad(\mathbf{1})^{[13-15]}$ which contain an $S, N$-bidentate coordinated arenethiolate. This complex and related chiral copper arenethiolates promote selective group transfer of Grignard reagents $(\mathrm{RMgX})$ to various organic substrates ${ }^{[16-24]}$, such as in chemo- and enantioselective 1,4 -addition to acyclic enones. ${ }^{[17]}$ Specifically, the latter marks the first reported case in which a copper

[a] Prof. Dr. ir. D. C. Koningsberger, Dr. M. Tromp,

Dr. J. A. van Bokhoven, Dr. J. H. Bitter

Debye Institute, Department of Inorganic Chemistry and Catalysis

Utrecht University

Sorbonnelaan 16, 3584 CA, Utrecht (The Netherlands)

Fax:(+31) 302511027

E-mail: d.c.koningsberger@chem.uu.nl.

[b] Dr. A. M. Arink, Prof. Dr. G. van Koten

Debye Institute, Department of Metal-Mediated Synthesis Utrecht

University

Padualaan 8, $3584 \mathrm{CH}$, Utrecht (The Netherlands) complex, here enantiopure $\mathbf{1}(R, R, R$ or $S, S, S)$, has been used in catalytic amounts to achieve enantioselective $\mathrm{C}-\mathrm{C}$ bond formation. ${ }^{[17,18,20,22,23]}$

The nature of the active cuprate species in these and related reactions is still largely unknown. Extended X-ray absorption fine structure (EXAFS) spectroscopy provides local structural information about a specific element in a compound. In contrast to X-ray diffraction (XRD), EXAFS spectroscopy does not require long-range ordering of the material. Therefore, EXAFS can be applied in structural studies of molecules in any state of aggregation. EXAFS has been used for the elucidation of the coordination sphere of metal centres in enzymes $^{[25,26]}$ and for the determination of the structure of compounds in both the solid and liquid state. ${ }^{[27]}$ EXAFS is unique in unravelling the structure of species under nonambient conditions as it can be applied in situ, under high pressure, temperature, and in the presence of gases. In organometallic chemistry the technique is complementary to IR spectroscopy, NMR spectroscopy and XRD. Studies of ${ }^{63,65} \mathrm{Cu}$ NMR spectra on organocopper complexes, which would potentially provide direct detailed information about the coordination sphere of the copper site(s) in organocuprates, is hampered by the large nuclear quadrupolar moment of the copper nucleus.

EXAFS spectroscopy of organocopper and cuprate mixtures is not straightforward. ${ }^{[25,26,28-32]}$ In the recent literature, 
several examples are given where $\mathrm{Cu}-\mathrm{Cu}$ coordinations were not detected or were very difficult to detect by EXAFS spectroscopy, although in some cases XRD and/or other chemical information strongly suggested that $\mathrm{Cu}$ neighbours around the photon-absorbing $\mathrm{Cu}$ ion were present. ${ }^{[28,30-35]}$ Sometimes $\mathrm{Cu}-\mathrm{Cu}$ contributions were not detected at all or unexpected $\mathrm{Cu}-\mathrm{Cu}$ contributions were found (wrong distances), in combination with incorrect $\mathrm{Cu}-\mathrm{C}$ or $\mathrm{Cu}-\mathrm{N}$ contributions. These problems are often encountered for $\mathrm{Cu}$ complexes in which $\mathrm{Cu} \cdots \mathrm{C}$ distances are in the same range as the $\mathrm{Cu} \cdots \mathrm{Cu}$ distances. ${ }^{[33]}$ Examples include organocopper reagents $(\mathrm{CuCN}+\mathrm{BuLi} \text { and } \mathrm{CuCN} \cdot 2 \mathrm{LiCl})^{[28,30-32]}$, and phenoxo-bridged dicopper(I) compounds ${ }^{[34]}$ as well as copper(I) thiolate clusters in the native protein $\left[\mathrm{Cu}-(\alpha \mathrm{EC})_{n} \mathrm{G}\right]$. $^{[35]}$

In a quest to understand the mechanistic aspects and to improve the copper-based catalytic systems for enantioselective synthesis, we have applied EXAFS spectroscopy to identify the catalytic site(s) of the key intermediates in our system. In this study a systematic method for the analysis of $\mathrm{Cu}$ K-edge EXAFS spectra is presented that allows the proper detection of $\mathrm{Cu}-\mathrm{Cu}$ contributions. The analysis method will be established by means of $\mathrm{Cu}$ K-edge EXAFS spectroscopy on the copper(I) arenethiolate species $\left(\mathrm{CuSC}_{6} \mathrm{H}_{4} \mathrm{CH}\right.$ $\left.(\mathrm{Me}) \mathrm{NMe}_{2}-2\right)_{3}$ (further abbreviated as $\left[\mathrm{Cu}_{3}(\mathrm{SAr})_{3}\right](\mathbf{1})$ see Figure 1). The structure of this $\mathrm{Cu}$ arenethiolate complex is

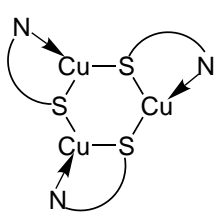

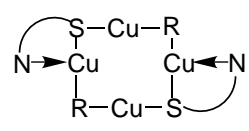

Figure 1. Schematic structures of $\mathrm{Cu}(\mathrm{I})$ arenethiolate complexes $\mathbf{1}$ and $\mathbf{2}$ as determined in the solid state by XRD, see references [13-15] for full structural details.

well known from single-crystal XRD data. ${ }^{[13-15]}$ The detectability of the $\mathrm{Cu}-\mathrm{Cu}$ coordination is investigated using the structural information obtained from single-crystal XRD as a starting point for the EXAFS analysis. The analysis strategy will be demonstrated by using the solid state $\left[\mathrm{Cu}_{3}\left(\mathrm{SAr}^{*}\right)_{3}\right]$ EXAFS spectra measured at room temperature. Subsequently, the analysis procedure will be applied to the EXAFS data of $\left[\mathrm{Cu}_{3}\left(\mathrm{SAr}^{*}\right)_{3}\right]$ dissolved in toluene measured at room temperature. The structure of a related mixed organo(arenethiolate)copper(I) aggregate $\left[\mathrm{Cu}_{4}(\mathrm{SAr})_{2}(\mathrm{Mes})_{2}\right]$ (2) (Figure 1), which contains distinctly different $\mathrm{Cu}$ sites, ${ }^{[21]}$ has been determined with EXAFS using the newly developed analysis procedure to confirm and demonstrate the validity of the developed analysis procedure.

The results of the EXAFS analysis provide essential information about the structure and dynamics of the complexes and of the vibrating $\mathrm{Cu}_{3} \mathrm{~S}_{3}$ ring of the trimeric $\mathrm{CuSAr}$ aggregate. This information will be important for an understanding of the formation of the kinetic intermediates between the organocopper catalyst precursor of the Grignard reagent and the substrate from which ultimately the $\mathrm{C}-\mathrm{C}$ coupled product is generated.

\section{EXAFS data-analysis methods}

Reference compounds: Theoretical references were used for the analysis of the $\mathrm{Cu}-\mathrm{S}, \mathrm{Cu}-\mathrm{N}, \mathrm{Cu}-\mathrm{Cu}$ and $\mathrm{Cu}-\mathrm{C}$ coordinations. The theoretical references were generated using the code FEFF 8. ${ }^{[36]}$ EXAFS data from reference compounds were used to calibrate the theoretical references: $\mathrm{Cu}$ foil $(7 \mu \mathrm{m})$ for $\mathrm{Cu}-\mathrm{Cu}, \mathrm{ZnS}$ for $\mathrm{Cu}-\mathrm{S}^{[37]}$ and copper phthalocyanine for both $\mathrm{Cu}-\mathrm{N}^{[37]}$ and $\mathrm{Cu}-\mathrm{C}$ since $\mathrm{N}$ and $\mathrm{C}$ are neighbouring atoms in the periodic table. The XDAP program $^{[38]}$ was used for the reference data fitting. The theoretical references were optimised as described in reference [39]. Table 1 gives the FEFF 8 input parameters. For all

Table 1. FEFF 8 input parameters used for the calculation of phase shifts and backscattering amplitudes. For all atom pairs a partially non-local potential is used. ${ }^{[36]}$

\begin{tabular}{lllcl}
\hline Atom pair & $\sigma^{2}\left[\AA^{2}\right]$ & $S_{0}{ }^{2}$ & $V_{r}[\mathrm{eV}]$ & $V_{i}[\mathrm{eV}]$ \\
\hline $\mathrm{Cu}-\mathrm{Cu}$ & 0.009 & 0.92 & 4.0 & 3.0 \\
$\mathrm{Cu}-\mathrm{S}$ & 0.005 & 0.88 & 2.5 & 3.0 \\
$\mathrm{Cu}-\mathrm{C}$ & 0.000 & 0.92 & 1.0 & 3.0 \\
$\mathrm{Cu}-\mathrm{N}$ & 0.002 & 0.84 & -3.1 & 3.0 \\
\hline
\end{tabular}

atom pairs a partially non-local potential was used. ${ }^{[36]} V_{\mathrm{i}}$ is estimated to be $3 \mathrm{eV} . S_{0}^{2}$, the Debye-Waller factor and $V_{\mathrm{r}}$ were varied until the generated references optimally fit in $R$ space the first coordination shell of the experimental EXAFS spectra of the above-mentioned reference compounds (see Table 2). The reference spectra were measured at room temperature so the references are optimised for these conditions. These calibrated references can then be used to fit the EXAFS data of the samples down to very low values of $k\left(k>2.5 \AA^{-1}\right){ }^{[39]}$

Table 2. Best fit results for the experimental data using the theoretical references, including fitting parameters. Fits were performed in $R$-space, $k^{3}$-weighted.

\begin{tabular}{lclrrrrrr}
\hline Shell & $N_{\text {XRD }}$ & $R_{\text {XRD }}[\AA]$ & \multicolumn{1}{c}{$N$} & $R[\AA]$ & $\Delta \sigma^{2}\left[\AA^{2}\right]$ & $E_{0}[\mathrm{eV}]$ & $\Delta k\left[\AA^{-1}\right]$ & $\Delta R[\AA]$ \\
\hline $\mathrm{Cu}-\mathrm{Cu}$ & 12 & 2.56 & 11.9 & 2.54 & 0.000 & -0.2 & $2.9-12.5$ & $1.5-2.7$ \\
$\mathrm{Cu}-\mathrm{S}$ & 4 & 2.35 & 4.0 & 2.35 & 0.001 & 0.4 & $2.9-12.5$ & $1.0-2.4$ \\
$\mathrm{Cu}-\mathrm{C}$ & 4 & 1.95 & 4.0 & 1.96 & 0.001 & -1.2 & $3.5-12.5$ & $1.0-2.0$ \\
$\mathrm{Cu}-\mathrm{N}$ & 4 & 1.93 & 4.0 & 1.94 & -0.001 & -2.3 & $3.5-12.5$ & $0.0-2.1$ \\
\hline
\end{tabular}

R-space fit: The EXAFS data were analysed by using the commercially available program XDAP. ${ }^{[38]}$ This program allows multiple-shell fitting in $R$-space by minimising the residuals between both the magnitude and imaginary part of the Fourier transforms of the data and the fit. $R$-space fitting has important advantages compared to the usually applied fitting in $k$-space, as is extensively discussed in reference [39]. $R$-space fitting makes Fourier filtering unnecessary, which is of great advantage if overlapping shells are present. Moreover, by choosing the proper window in $R$-space the background subtraction errors and the presence of further higher shells can be avoided. Another important advantage is that the amount of information (number of independent data points, vide infra) is not decreased by shortening the range of reliable data in $k$-space due to Fourier filtering errors. 
Variance and number of independent data points: The errors in the structural parameters were calculated from the covariance matrix taking into account the statistical noise of the EXAFS data and the correlations between the different coordination parameters. The standard deviation per data point was estimated by averaging three data scans. The number of independent data points $\left(N_{\text {indp }}\right)$ was determined as outlined in the "Reports on Standard and Criteria in XAFS Spectroscopy" ${ }^{"[0]}$ and is calculated as shown in Equation (1).

$N_{\text {indp }}=\frac{2 * \Delta k * \Delta R}{\pi}+2$

A large number of independent data points is important, especially if several contributions are present and overlapping, to reliably fit the data reliably and account for possible anti-phase behaviour of different contributions as shown in this study.

The variances of the magnitude and imaginary part of the Fourier transforms of fit and data were calculated according to Equation (2).

$k^{n}$ variance $=\frac{\int\left[k^{n}\left(\mathrm{FT}_{\text {model }}(R)-\mathrm{FT}_{\text {exp }}(R)\right]^{2} \mathrm{~d} R\right.}{\int\left[k^{n} \mathrm{FT}_{\text {exp }}(R)\right]^{2} \mathrm{~d} R} \times 100$

Difference file technique: The difference file technique was applied together with phase-corrected Fourier transforms to resolve the different contributions in the EXAFS data. ${ }^{[39,41]}$ The difference file technique allows the observation of each individual contribution with respect to the other contributions present in the EXAFS spectrum. The experimental $\chi_{\mathrm{EXP}}(k)$ in the range $R_{\min }$ to $R_{\max }$ can be described by summation of different model EXAFS contributions $\chi_{\mathrm{MOD}, j}(k)$, describing each coordination shell as shown by Equation (3).

$\chi_{\mathrm{EXP}, j}(k)=\sum_{j=1}^{\text {Shells }} \chi_{\mathrm{MOD}, j}(k)$

For each individual fitted contribution $m$ Equation should then logically be valid.

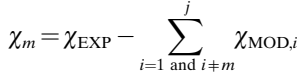

The right side of Equation (4) is further denoted as the difference file of shell $\mathrm{m}$. A sensitive and practical method to check whether a contribution is statistically significant consists of a comparison of the amplitude of $\chi_{m}$ with the noise level present in the difference file (the noise in the difference file is essentially the same as the noise in the experimental data). The total variances between total fit and data determine the correctness of the total analysis of the obtained EXAFS data. Moreover, the use of the difference file technique enables one to observe and examine the individual contributions and their position, intensity and influence on each other during the analysis procedure.

Weight factor $\boldsymbol{k}^{\boldsymbol{n}}$ : The phase shift and backscattering amplitude of each neighbouring atom are in principle element specific and have a characteristic dependency of the wavefactor $k$. Normally, a combination of a $k^{0}$ - and $k^{3}$-weighting during the EXAFS data-analysis is used in order to separate each individual contribution. ${ }^{[39]}$ In this study the use of both $k^{0}$ - and $k^{3}$-weighting was crucial in order to unravel interference effects of higher coordination shells. Principally, different $k$-weightings should yield identical results and a good fit in one weighting should be good in all other weightings applied. ${ }^{[39]}$ As found in this study to be of vital importance, a fit in $k^{n}$-weighting is only considered correct if other $k^{n}$ weightings show minima in variances too. In a system with many contributions such as in this case, a single $k^{n}$-weighting may well show several minima in variances obscuring the true minimum.

\section{Results}

\section{Single-crystal $\mathrm{X}$-ray diffraction on $\left[\mathrm{Cu}_{3}\left(\mathrm{SAr}^{*}\right)_{3}\right]$ :}

The crystal structure of the copper(I) arenethiolate $\left[\mathrm{Cu}_{3^{-}}\right.$ $\left.\left(\mathrm{SAr}^{*}\right)_{3}\right](\mathbf{1})$ is known from single-crystal X-ray diffraction data. ${ }^{[13-15]}$ The molecular structure of $\mathbf{1}$ shows a triangular trimeric aggregate which comprises three identical (crystallographically related) CuSAr units that are held together by bridging of the thiolate sulfur atom between adjacent copper atoms. This structure is shown in Figure 2 in which only one of

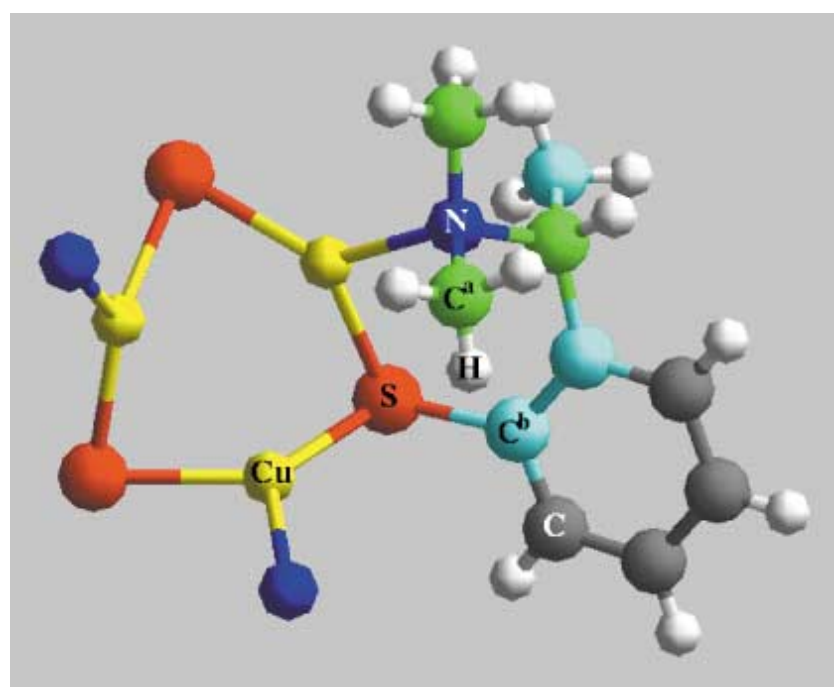

Figure 2. $\left[\mathrm{Cu}_{3}\left(\mathrm{SAr}^{*}\right)_{3}\right](\mathbf{1})$ showing only one of the three chelating arms. The position of the other two arms is only indicated by the presence of the nitrogen atom from each. The $\mathrm{C}$ atoms at about the same $\mathrm{Cu} \cdots \mathrm{C}$ distance have identical colour.

the three chelating arms is displayed completely. The position of the other two arms is indicated by showing only the nitrogen atom of each. The crystallographic $\mathrm{Cu}$-neighbour distances are given in Table $3 .^{[13-15]}$ Three neighbouring

Table 3. Single-crystal X-ray diffraction data for $\left[\mathrm{Cu}_{3}(\mathrm{SAr})_{3}\right]$ at $110 \mathrm{~K}$.

\begin{tabular}{lll}
\hline $\mathrm{Ab}-\mathrm{Sc}$ pair $^{[\mathrm{a}]}$ & $N$ & $R[\AA]^{[\mathrm{b}]}$ \\
\hline $\mathrm{Cu}-\mathrm{N}$ & 1 & 2.08 \\
$\mathrm{Cu}-\mathrm{S}$ & 2 & $2.21( \pm 0.02)$ \\
$\mathrm{Cu} \cdots \mathrm{Cu}$ & 2 & $2.83( \pm 0.00)$ \\
$\mathrm{Cu} \cdots \mathrm{C}^{\mathrm{a}}$ & 3 & $2.96( \pm 0.02)$ \\
$\mathrm{Cu} \cdots \mathrm{C}^{\mathrm{b}}$ & 3 & $3.31( \pm 0.14)$ \\
\hline
\end{tabular}

$[\mathrm{a}] \mathrm{Ab}=$ absorber $; \mathrm{Sc}=$ scatterer. $[\mathrm{b}]$ The maximum deviation in distances is given in parentheses. 
carbon atoms (denoted $\mathrm{C}^{\mathrm{a}}$ ) are located at a distance of $2.96 \AA$; three other carbon atoms (denoted $\mathrm{C}^{\mathrm{b}}$ ), also relevant for the EXAFS analysis, can be distinguished at a distance of $3.31 \AA$ (see also Figure 2). The values for the coordination distances for the $\mathrm{Cu}-\mathrm{S}, \mathrm{Cu}-\mathrm{Cu}, \mathrm{Cu}-\mathrm{C}^{\mathrm{a}}$ and $\mathrm{Cu}-\mathrm{C}^{\mathrm{b}}$ pairs are average values and the maximum deviation in the distance is given in parentheses in Table 3.

EXAFS data of $\left[\mathrm{Cu}_{3}\left(\mathrm{SAr}^{*}\right)_{3}\right]$ in the solid state and solution (at room temperature): Figure 3 displays the $\mathrm{Cu}$ K-edge EXAFS data of $\left[\mathrm{Cu}_{3}\left(\mathrm{SAr}^{*}\right)_{3}\right]$ obtained in the solid state (solid line) and solution (dotted line). The signal-to-noise ratio is

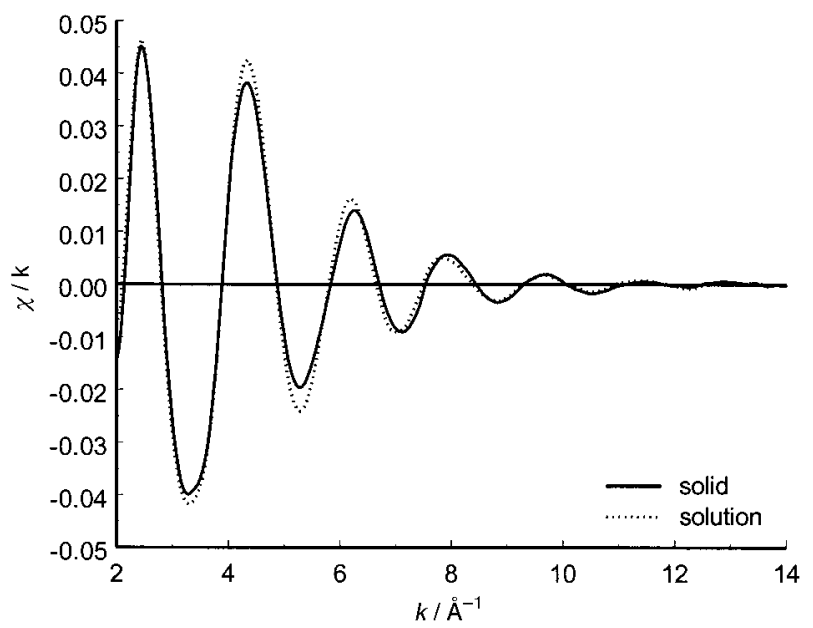

Figure 3. Raw EXAFS data of $\left[\mathrm{Cu}_{3}\left(\mathrm{SAr}^{*}\right)_{3}\right]$ in the solid state (solid line) and in solution (dotted line).

very good, the data can be analysed up to $k=12.5 \AA^{-1}$. The corresponding $k^{0}$ - and $k^{3}$-weighted Fourier transforms (for $2.9<k<12.5 \AA^{-1}$ ) are given respectively in Figures $4 \mathrm{a}$ and $4 \mathrm{~b}$. It can be observed that the intensity in the Fourier Transforms for the sample in solution is in both $k$-weightings slightly higher. Moreover, for $R>\approx 2 \AA$ some small but significant changes in the imaginary parts can be observed. A very important observation, and crucial for the EXAFS data analysis to be applied in this study, is the fact that for the $k^{3}$ weighted Fourier transforms almost no intensity is observed for $R>2.2 \AA$, whereas in the $k^{0}$-weighted Fourier transforms there is.

First, the $\left[\mathrm{Cu}_{3}\left(\mathrm{SAr}^{*}\right)_{3}\right]$ sample in solid state was analysed since the crystal structure of this sample is known from single crystal XRD. For the initial analysis in $R$-space of the $\left[\mathrm{Cu}_{3}\left(\mathrm{SAr}^{*}\right)_{3}\right]$, EXAFS data a $k^{0}$-weighted factor was used. In the next step the correctness of the fit was checked by using a higher $k$-weighting $\left(k^{1}, k^{2}, k^{3}\right)$. Additionally, the influence of an increasing number of coordination shells is observed carefully. The crystallographically known values for the coordination numbers $(\mathrm{N})$ and distances $(R)$ (Table 3) were used as starting input parameters. The data were analysed by using an $R$-space fit with $k$-range of $2.9<k<12.5 \AA^{-1}$ and $R$ range of $1.0<R<4.0 \AA$. Both the absolute and the imaginary part of the Fourier transform were optimised. Each shell was fitted by iteratively allowing the parameters $\left(R, \mathrm{~N}, \Delta \sigma^{2}\right.$ and $\Delta E_{0}$ ) of that shell to be free. An increasing number of
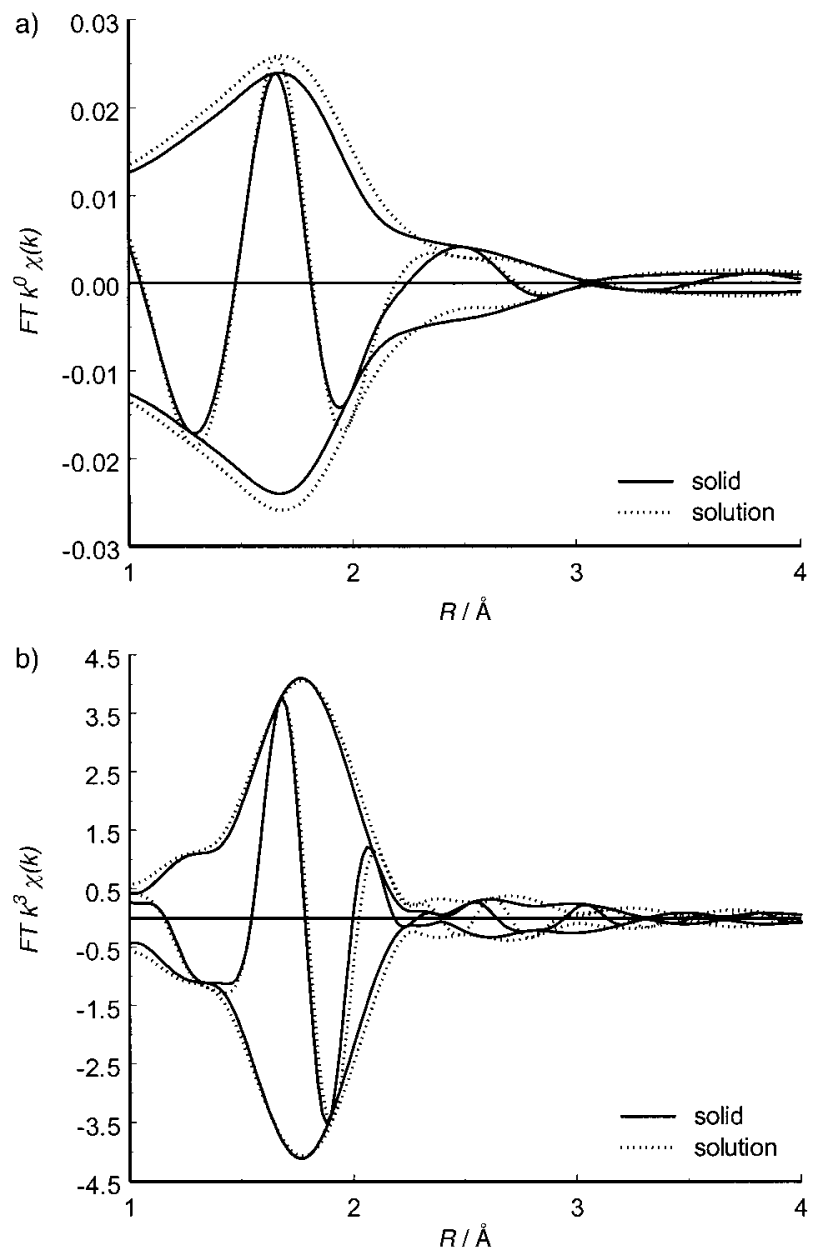

Figure 4. Fourier transforms of the EXAFS data of $\left[\mathrm{Cu}_{3}\left(\mathrm{SAr}^{*}\right)_{3}\right]$ in the solid state (solid line) and in solution (dotted line) for $2.9<\mathrm{k}<12.5 \AA^{-1}$ a) $k^{0}$-weighted; b) $k^{3}$-weighted.

coordination shells were used to fit the data. A two-shell fit $(\mathrm{Cu}-\mathrm{N}, \mathrm{Cu}-\mathrm{S})$, a three-shell fit $(\mathrm{Cu}-\mathrm{N}, \mathrm{Cu}-\mathrm{S}, \mathrm{Cu}-\mathrm{Cu})$, a fourshell fit $\left(\mathrm{Cu}-\mathrm{N}, \mathrm{Cu}-\mathrm{S}, \mathrm{Cu}-\mathrm{Cu}, \mathrm{Cu}-\mathrm{C}^{\mathrm{a}}\right)$ and a five-shell fit $\left(\mathrm{Cu}-\mathrm{N}, \mathrm{Cu}-\mathrm{S}, \mathrm{Cu}-\mathrm{Cu}, \mathrm{Cu}-\mathrm{C}^{\mathrm{a}}, \mathrm{Cu}-\mathrm{C}^{\mathrm{b}}\right)$ were used to observe the influence of an increasing number of coordination shells (Table 4).

The final five-shell total fit for $\left[\mathrm{Cu}_{3}\left(\mathrm{SAr}^{*}\right)_{3}\right]$ at room temperature ( $k^{0}$-weighted) is given in Figure $5 \mathrm{a}$. To show that the obtained fit is correct, the fit in an other $k$-weighting, $k^{3}$, is shown in Figure $5 b$, with the fit variances given in Table 4. As the difference file technique was used for the analysis of the EXAFS spectra, the individual contributions can be analysed separately and should also fit correctly to be able to conclude a good analysis. In Figure 6 the Fourier transforms of the individual difference files are given, including the fits for the individual shells. The $\mathrm{Cu}-\mathrm{N}$ contribution, displayed in Figure $6 \mathrm{a}$ is fitted very well in the analysis range applied $(1.0<$ $R<4.0 \AA$ ). The $\mathrm{Cu}-\mathrm{S}$ single-shell is the largest contribution in the analysis and fits perfectly as can been seen in Figure $6 \mathrm{~b}$. In Figure $6 \mathrm{c}$ the $\mathrm{Cu}-\mathrm{Cu}$ contribution is shown. The $\mathrm{Cu}-\mathrm{C}^{\mathrm{a}}$ contribution given in Figure $6 \mathrm{~d}$ fits very well and the $\mathrm{Cu}-\mathrm{C}^{\mathrm{b}}$ contribution, which is displayed in Figure 6e, shows little noise on the measured data. It can be observed that both 
Table 4. EXAFS analysis of $\left[\mathrm{Cu}_{3}(\mathrm{SAr})_{3}\right]$ (solid, room temperature), $k^{0}$ weighted fit, $2-5$ shells. ${ }^{[a]}$

\begin{tabular}{lccccccc}
\hline $\mathrm{Ab}-$ Sc Pair ${ }^{[\mathrm{b}]}$ & $N$ & $\begin{array}{l}R \\
{[\AA]}\end{array}$ & $\begin{array}{l}\Delta \sigma^{2} \\
{\left[\AA^{2}\right]}\end{array}$ & $\begin{array}{r}\Delta E_{0} \\
{[\mathrm{eV}]}\end{array}$ & & $\begin{array}{l}\text { Var. } \\
\text { Im. }^{[\mathrm{b}]}\end{array}$ & $\begin{array}{l}\text { Var. } \\
\text { Abs. }^{[\mathrm{b}]}\end{array}$ \\
\hline $\begin{array}{l}2 \text {-shell fit } \\
\mathrm{Cu}-\mathrm{N}\end{array}$ & 2.1 & 2.20 & 0.040 & 7.8 & $k^{0}:$ & 2.0 & 0.96 \\
$\mathrm{Cu}-\mathrm{S}$ & 2.0 & 2.21 & 0.000 & 2.4 & $k^{3}:$ & 4.3 & 2.0 \\
3 -shell fit & & & & & & & \\
$\mathrm{Cu}-\mathrm{N}$ & 1.1 & 2.04 & 0.008 & 9.3 & $k^{0}:$ & 0.17 & 0.083 \\
$\mathrm{Cu}-\mathrm{S}$ & 2.0 & 2.22 & 0.002 & -0.2 & $k^{3}:$ & 1.4 & 0.64 \\
$\mathrm{Cu} \cdots \mathrm{Cu}$ & 6.9 & 2.96 & 0.040 & -6.9 & & & \\
$4-$ shell fit & & & & & & & \\
$\mathrm{Cu}-\mathrm{N}$ & 1.0 & 2.08 & 0.005 & 1.0 & $k^{0}:$ & 0.037 & 0.063 \\
$\mathrm{Cu}-\mathrm{S}$ & 2.0 & 2.21 & 0.003 & 0.4 & $k^{3}:$ & 0.44 & 0.21 \\
$\mathrm{Cu} \cdots \mathrm{Cu}$ & 2.8 & 3.00 & 0.014 & -3.7 & & & \\
$\mathrm{Cu} \cdots \mathrm{C}^{\mathrm{a}}$ & 3.1 & 3.15 & 0.007 & 5.9 & & & \\
$5-$ shell fit & & & & & & & \\
$\mathrm{Cu}-\mathrm{N}$ & 1.0 & 2.05 & 0.001 & 0.6 & $k^{0}:$ & 0.017 & 0.012 \\
$\mathrm{Cu}-\mathrm{S}$ & 1.9 & 2.23 & 0.003 & -1.4 & $k^{3}:$ & 0.20 & 0.10 \\
$\mathrm{Cu} \cdots \mathrm{Cu}$ & 1.7 & 2.84 & 0.016 & 1.7 & & & \\
$\mathrm{Cu} \cdots \mathrm{C}^{\mathrm{a}}$ & 3.3 & 2.99 & 0.010 & 7.9 & & & \\
$\mathrm{Cu} \cdots \mathrm{C}^{\mathrm{b}}$ & 2.8 & 3.45 & 0.013 & -1.3 & & & \\
\hline
\end{tabular}

[a] $N_{\text {indp }}=20$. Fit: $R$-space, $2.89<k<12.50 ; 1.0<R<4.0$, all parameters iteratively refined. [b] $\mathrm{Ab}=$ absorber; $\mathrm{Sc}=$ scatterer; Var. Im. and Var. Abs. are the variances of the fit of the Imaginary and Absolute part, respectively.
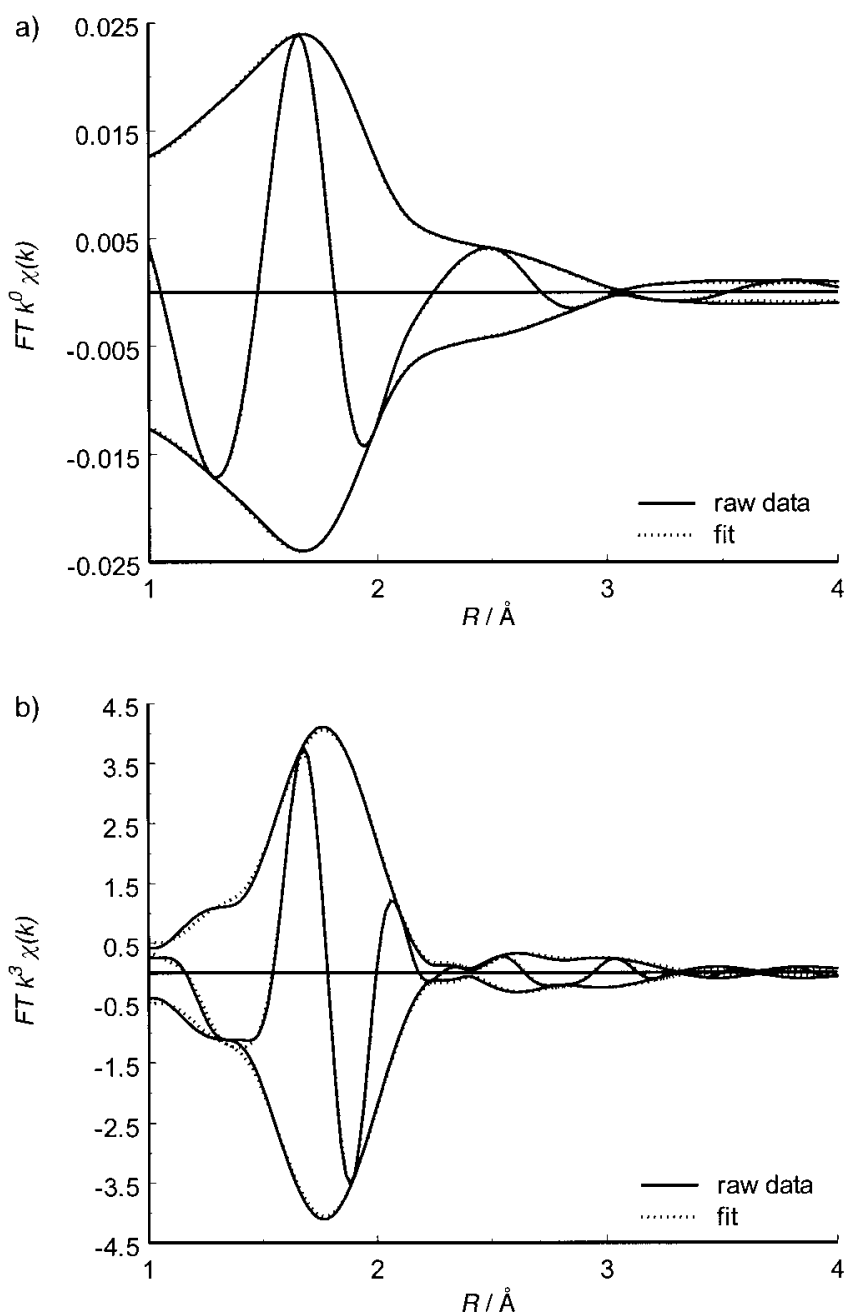

Figure 5. Fourier Transforms of raw data (solid line) and $R$-space fit (dotted line) $\left(2.9<k<12.5 \AA^{-1}\right.$ and $1.0<R<4.0 \AA$ ) with five coordination shells of $\left[\mathrm{Cu}_{3}\left(\mathrm{SAr}^{*}\right)_{3}\right]$ in the solid state. a) $k^{0}$ weighted; b) $k^{3}$-weighted.
$\mathrm{Cu}-\mathrm{C}$ contributions are larger than the $\mathrm{Cu}-\mathrm{Cu}$ contribution. Only little noise can be seen in the Fourier Transforms of the difference files of the smallest contributions $\left(\mathrm{Cu}-\mathrm{Cu}, \mathrm{Cu}-\mathrm{C}^{\mathrm{a}}\right.$, $\left.\mathrm{Cu}-\mathrm{C}^{\mathrm{b}}\right)$. From these Figures it is clear that these individual contributions are well above the noise, and are thus significant, and that they are fitted very well. The final EXAFS coordination parameters are summarised in Table 4.

The $\left[\mathrm{Cu}_{3}\left(\mathrm{SAr}^{*}\right)_{3}\right]$ was also measured in solution, in this case, toluene. In Figure $7 \mathrm{a}$ the Fourier transforms $(2.9<\mathrm{k}<$ $12.5 \AA^{-1}$ ) of both the $k^{0}$ - and $k^{3}$-weighted spectrum are given. In the $k^{3}$-weighted spectrum a very low intensity of the signal is observed between 2 and $2.5 \AA$, whereas in the $k^{0}$-weighted spectrum a clear signal remains present (note the differences in axis). A five-shell analysis has been performed by using a $k^{0}$-weighting. The crystallographic results are used as starting input parameters and the shells are iteratively refined leaving step by step (shell by shell) all parameters free. The $k^{0}$ weighted $R$-space fit is shown in Figure $7 \mathrm{~b}$ and the results are given in Table 5. The correctness of the fit is also shown in Figure $7 \mathrm{c}$ for the $k^{3}$-weighted fit using the obtained parameters, with the calculation variances given in Table 5 .

Analysis of $\mathrm{Cu}_{4}(\mathrm{SAr})_{2}(\mathrm{Mes})_{2}$ : The structure of the tetranuclear aggregate $\mathrm{Cu}_{4}(\mathrm{SAr})_{2}(\mathrm{Mes})_{2}$ (2) has two non-equivalent $\mathrm{Cu}$ atoms and comprises the binding of two different anions, the arenethiolate anion and the mesityl anion. ${ }^{[21]}$ The $\mathrm{Cu}$ neighbour coordination numbers $\left(N_{\mathrm{xrd}}\right)$ and distances $\left(R_{\mathrm{xrd}}\right)$ of this aggregate as obtained with single-crystal XRD are given in Table 6. ${ }^{[21]}$ Both the $k^{0}$ - and the $k^{3}$-weighted Fourier transforms of the measured EXAFS data $(2.89<k<$ $12.5 \AA^{-1}$ ) are given in Figure $8 \mathrm{a}$. It can be seen that using different weightings for the Fourier transforms leads to a loss in intensity in several (different) $R$-ranges. So, in different $R$ ranges, a different $k$-weighting will result in the most reliable fit. The fitting procedure is carried out using a $k^{0}$-weighting for $1.0<R<1.7 \AA$ and $2.2<R<3.0 \AA$, and a $k^{3}$-weighting for $1.0<R<2.5 \AA$. During the fitting procedure the coordination numbers were fixed and all other parameters were iteratively refined. The final fit is shown in Figure $8 \mathrm{~b}$ and Figure $8 \mathrm{c}$ for the $R$-space fit with $k^{0}$ and $k^{3}$ weightings, respectively. The obtained parameters are given in Table 6 . In both $k$-weightings an excellent total fit is obtained, showing the correctness of the analysis procedure.

\section{Discussion}

Determination of the weight factor(s) used for the EXAFS data-analysis: detection of anti-phase behaviour: Fitting the spectrum of a compound with a well-known structure provides information about the reliability of the EXAFS data-analysis procedure. The influence of different $k$-weightings and inclusion of an increasing number of shells on the fit variances can then be studied. The difference file technique can separate the single shells and compare the different shells to each other. The goodness of the fit can be observed and the statistical significance of the individual contributions can be evaluated. Fitting in $R$-space is essential to prevent truncation errors. Using a Fourier transform of the EXAFS data and 

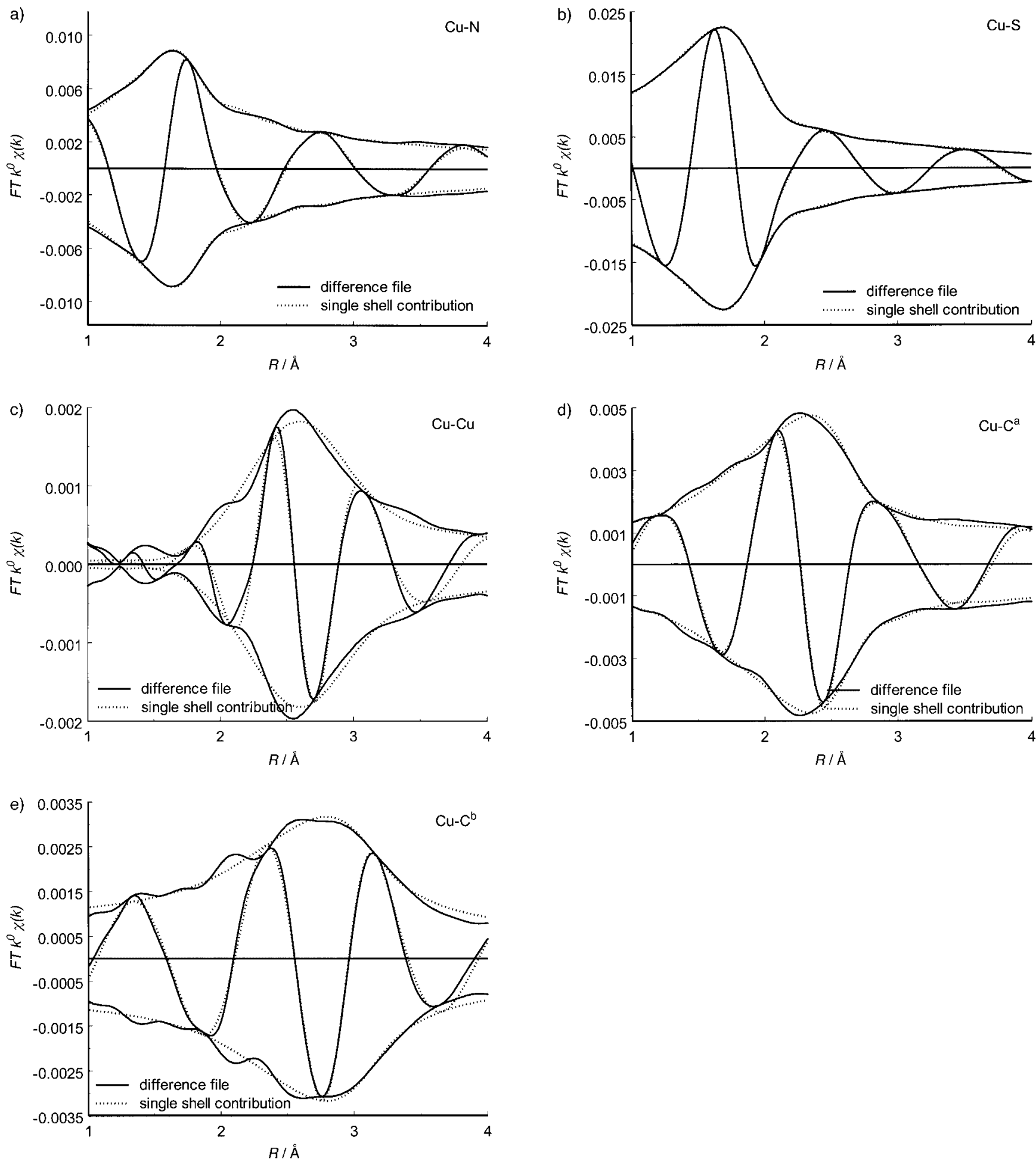

Figure 6. Fitted single shell contributions (dotted line) and difference files (solid line) of five shell $R$-space fit $\left(k^{0}, 2.9<k<12.5,1.0<R<4.0\right)$ of $\left[\mathrm{Cu}_{3}\left(\mathrm{SAr}^{*}\right)_{3}\right]$ in solid state measured at room temperature. a) $\left.\left.\left.\mathrm{Cu}-\mathrm{N} ; \mathrm{b}\right) \mathrm{Cu}-\mathrm{S} ; \mathrm{c}\right) \mathrm{Cu}-\mathrm{Cu} ; \mathrm{d}\right) \mathrm{Cu}^{-} \mathrm{C}^{\mathrm{a}} ;$ e) $\mathrm{Cu}^{-} \mathrm{C}^{\mathrm{b}}$.

applying different weightings can immediately reveal the presence of anti-phase behaviour of the EXAFS oscillations of the different coordination shells. In the literature, the peaks observed in the total Fourier Transform of the EXAFS data are regularly simply assigned to the separate contributions in a spectrum. However, overlap of different shells (especially in case of anti-phase behaviour) can significantly change the shape and intensity of the total Fourier Transform peak(s) or shift the position of the total peak, ${ }^{[39]}$ as is also demonstrated in this study. In this way the amount and position of contributions can be underestimated and interpreted wrongly.

For the $\left[\mathrm{Cu}_{3}\left(\mathrm{SAr}^{*}\right)_{3}\right]$ sample in the solid and liquid state measured at room temperature an $R$-space fit of a $k^{0}$-weighted EXAFS including five coordination shells leads to a good agreement with the results of single-crystal XRD (Tables 4 

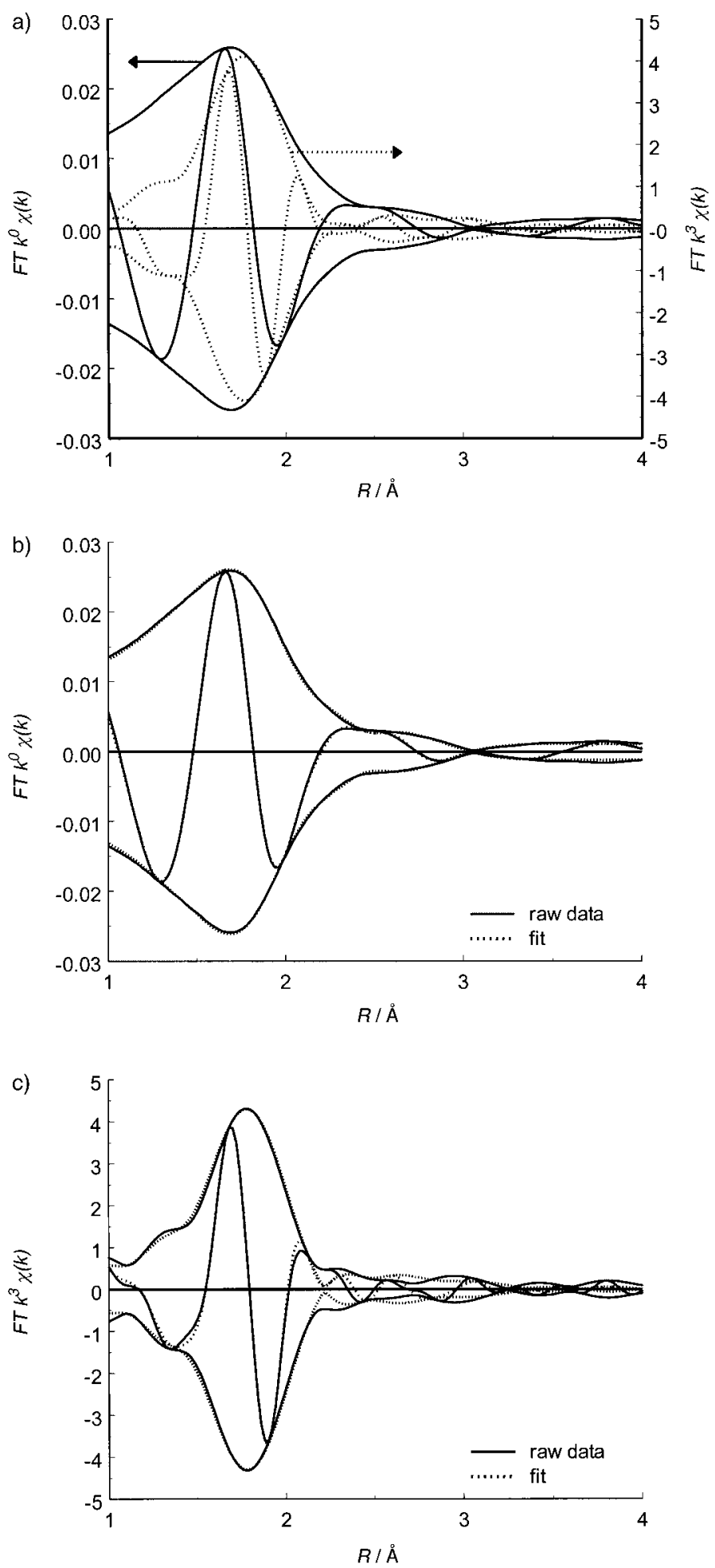

Figure 7. a) Fourier transform $\left(2.9<k<12.5 \AA^{-1}\right)$ of raw EXAFS data of $\left[\mathrm{Cu}_{3}(\mathrm{SAr})_{3}\right]$ in solution $k^{0}$-weighted (solid line), $k^{3}$-weighted (dotted line); b) $k^{0}$-weighted and c) $k^{3}$-weighted $R$-space fit $\left(2.9<k<12.5 \AA^{-1}\right.$ and $1.0<R<4.0 \AA$ ) with five coordination shells of $\left[\mathrm{Cu}_{3}\left(\mathrm{SAr}^{*}\right)_{3}\right]$ in solution (at room temperature).

and 5). Both a $k^{0}$ - and a $k^{3}$-weighting have to be used for the analysis of $\mathrm{Cu}_{4}(\mathrm{SAr})_{4}(\mathrm{Mes})_{2}$ (Table 6). When the data analysis procedure has been performed using the best $k$-weighting as a starting point, an important check has to be performed. Only if the fitting parameters obtained also result in a good
Table 5. EXAFS analysis results of $\left[\mathrm{Cu}_{3}(\mathrm{SAr})_{3}\right]$ (solution, room temperature), $k^{0}$-weighted five-shell fit. ${ }^{[a]}$

\begin{tabular}{llllrlll}
\hline $\mathrm{Ab}-\mathrm{Sc}$ Pair ${ }^{[\mathrm{b}]}$ & $N$ & $\begin{array}{l}R \\
{[\AA]}\end{array}$ & $\begin{array}{l}\Delta \sigma^{2} \\
{\left[\AA^{2}\right]}\end{array}$ & $\begin{array}{c}\Delta E_{0} \\
{[\mathrm{eV}]}\end{array}$ & $\begin{array}{l}\text { Var. } \\
\text { Im. } .^{[\mathrm{b}]}\end{array}$ & $\begin{array}{l}\text { Var. } \\
\text { Abs. }{ }^{[\mathrm{b}]}\end{array}$ \\
\hline $\mathrm{Cu}-\mathrm{N}$ & 1.1 & 2.01 & 0.003 & 1.0 & $k^{0}:$ & 0.07 & 0.04 \\
$\mathrm{Cu}-\mathrm{S}$ & 1.9 & 2.25 & 0.004 & -2.0 & $k^{3}:$ & 0.32 & 0.16 \\
$\mathrm{Cu} \cdots \mathrm{Cu}$ & 2.1 & 2.83 & 0.018 & -5.7 & & & \\
$\mathrm{Cu} \cdots \mathrm{C}^{\mathrm{a}}$ & 2.8 & 2.95 & 0.012 & 11.0 & & & \\
$\mathrm{Cu} \cdots \mathrm{C}^{\mathrm{b}}$ & 2.6 & 3.50 & 0.015 & -0.9 & & & \\
\hline
\end{tabular}

[a] $N_{\text {indp }}=20$. Fit: $R$-space, $2.89<k<12.50 ; 1.0<R<4.0$, all parameters iteratively refined. [b] $\mathrm{Ab}=$ absorber; $\mathrm{Sc}=$ scatterer; Var. Im. and Var. Abs. are the variances of the fit of the Imaginary and Absolute part, respectively.

Table 6. EXAFS analysis of $\mathrm{Cu}_{4}(\mathrm{SAr})_{2}(\mathrm{Mes})_{2}$. ${ }^{\text {[a] }}$

\begin{tabular}{lccrrrllll}
\hline $\mathrm{Ab}-\mathrm{Sc}$ & $N$ & $\begin{array}{l}R \\
{[\AA]}\end{array}$ & $\begin{array}{l}\Delta \sigma^{2} \\
{\left[\AA^{2}\right]}\end{array}$ & \multicolumn{1}{c}{$\begin{array}{c}\Delta E_{0} \\
{[\mathrm{eV}]}\end{array}$} & $\begin{array}{l}\text { Var. } \\
\left.\text { Im. }{ }^{[\mathrm{b}]}\right]\end{array}$ & $\begin{array}{l}\text { Var. } \\
\left.\text { Abs. } .^{[\mathrm{b}]}\right]\end{array}$ & $N_{\text {lit }}$ & $\begin{array}{l}R_{\text {lit }} \\
{[\AA]}\end{array}$ \\
\hline $\mathrm{Cu}-\mathrm{C}^{\mathrm{a}}$ & 1.0 & 1.91 & 0.008 & 6.4 & $k^{3}:$ & 0.04 & 0.02 & 1 & 2.02 \\
$\mathrm{Cu}-\mathrm{N}$ & 0.5 & 2.27 & -0.006 & -7.3 & $k^{0}:$ & 0.24 & 0.05 & 0.5 & 2.14 \\
$\mathrm{Cu}-\mathrm{S}$ & 1.0 & 2.21 & -0.003 & -7.3 & & & & 1 & 2.22 \\
$\mathrm{Cu} \cdots \mathrm{Cu}^{\mathrm{a}}$ & 1.0 & 2.44 & 0.002 & -0.7 & & & & 1 & 2.40 \\
$\mathrm{Cu} \cdots \mathrm{Cu}^{\mathrm{b}}$ & 1.5 & 2.74 & 0.017 & 5.7 & & & & 1.5 & 2.74 \\
$\mathrm{Cu} \cdots \mathrm{C}^{\mathrm{b}}$ & 3.0 & 2.96 & 0.001 & 13.2 & & & & 3 & 2.93
\end{tabular}

[a] $N_{\text {indp }}=14$. Fit: $R$-space, $2.89<k<12.50 ; k^{0}$-weighted $1<R<1.7$ and $2.2<$ $R<3$ and $k^{3}$-weighted $1<R<2.5$. N fixed, all other parameters iteratively refined. $[\mathrm{b}] \mathrm{Ab}=$ absorber; $\mathrm{Sc}=$ scatterer; Var. Im. and Var. Abs. are the variances of the fit of the Imaginary and Absolute part, respectively.

agreement in (all) other $k$-weightings, a correct EXAFS data analysis is concluded. This study makes it clear that criteria solely based on analysis of EXAFS data can be established, which can be applied straightforwardly to determine the structure of unknown compounds.

EXAFS data-analysis of $\left[\mathrm{Cu}_{3}\left(\mathrm{SAr}^{*}\right)_{3}\right]$ (1) in the solid state and solution: statistical significance and analysis of anti-phase behaviour: As shown in Figure 4, a $k^{3}$-weighted Fourier transform of the EXAFS data leads to a very small amplitude of the higher shells peaks. Freeing all parameters iteratively resulted in a good fit with coordination parameters, which are in good agreement with the results of single crystal XRD when using $k^{0}$-weighting for the analysis of the room temperature data. These results can be understood by a more detailed examination of the single-shell EXAFS contributions of the optimised fit.

Figure $9 \mathrm{a}$ displays the calculated $\mathrm{Cu}-\mathrm{Cu}, \mathrm{Cu}-\mathrm{C}^{\mathrm{a}}$, and $\mathrm{Cu}-\mathrm{C}^{\mathrm{b}}$ EXAFS functions determined for the analysis of the solid state EXAFS data. All EXAFS oscillations are well above the noise band of \pm 0.00025 . A maximum noise level of 0.0005 is determined in the raw EXAFS data at $k=14 \AA^{-1}$. Not only from the Fourier transforms of the difference files as plotted in Figure 6 but also from Figure 9 it can therefore be concluded that these higher shell contributions are statistically significant. Moreover, it can be seen also that the $\mathrm{Cu}-\mathrm{Cu}$ and the $\mathrm{Cu}-\mathrm{C}^{\mathrm{b}}$ EXAFS functions are opposite in phase to the $\mathrm{Cu}-\mathrm{C}^{\text {a }}$ EXAFS function in the range of $4.0<k<9.0 \AA^{-1}$. This results in a strong damping of the total higher shell EXAFS contributions $\left(\mathrm{Cu}-\mathrm{Cu}+\mathrm{Cu}-\mathrm{C}^{\mathrm{a}}+\mathrm{Cu}-\mathrm{C}^{\mathrm{b}}\right)$ at these high $k$ - 

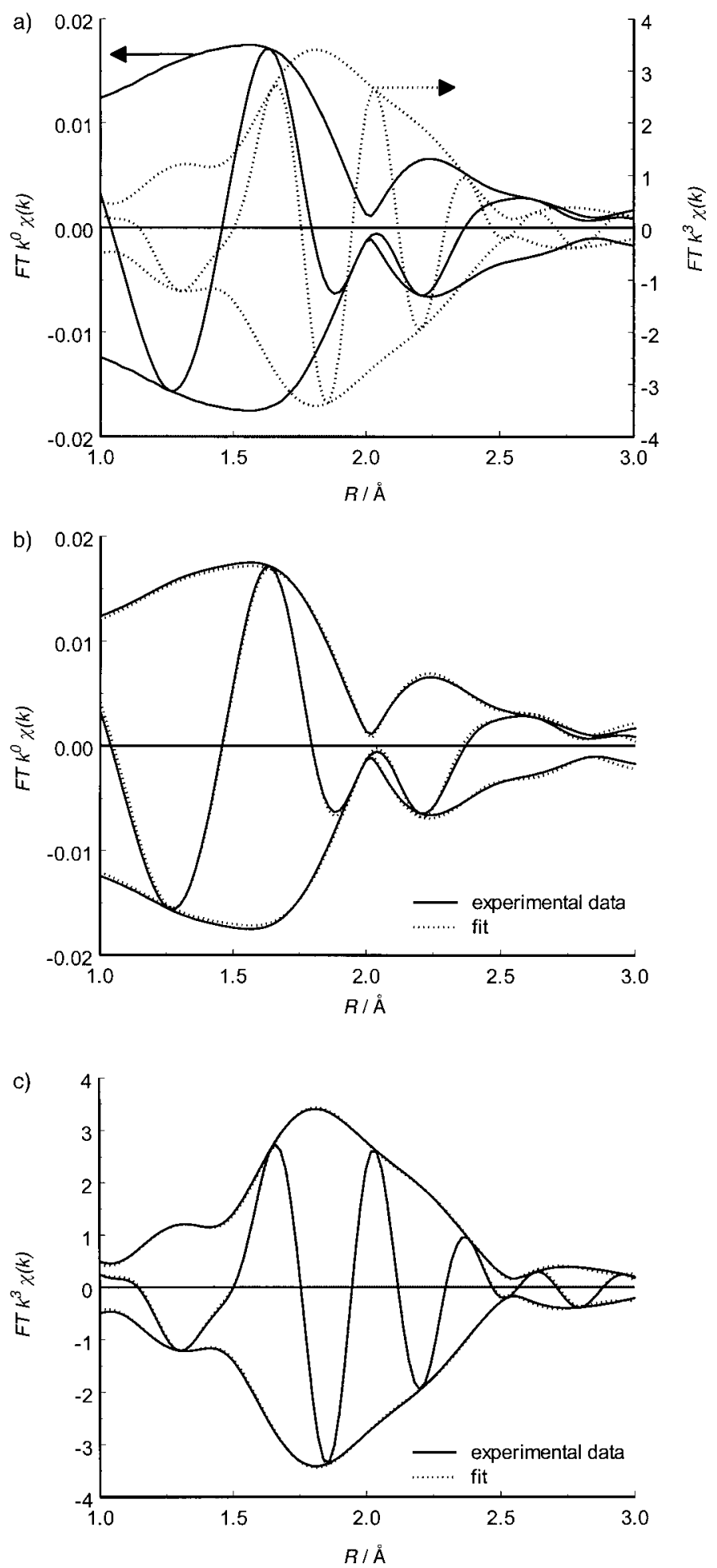

Figure 8. a) Fourier transforms $\left(2.9<k<12.5 \AA^{-1}\right)$ of raw EXAFS data of $\left[\mathrm{Cu}_{4}(\mathrm{SAr})_{2}(\mathrm{Mes})_{2}\right]$ in the solid state measured at room temperature, $k^{0}$ weighted (solid line) and $k^{3}$-weighted (dotted line); b) $k^{0}$-weighted and c) $k^{3}$-weighted $R$-space fit $\left(2.9<k<12.5 \AA^{-1}\right.$ and $\left.1.0<R<3.0 \AA\right)$ with six coordination shells of $\left[\mathrm{Cu}_{4}(\mathrm{SAr})_{2}(\mathrm{Mes})_{2}\right]$ measured at room temperature.

values, which is shown in Figure 9b. A high $k$-weighting will therefore make the fit insensitive to these higher shells.

Interference effects have a strong influence on the analysis of the $\mathrm{Cu}-\mathrm{Cu}$ contributions. As can be observed in Table 4 only after inclusion of the fifth shell $\left(\mathrm{Cu}-\mathrm{C}^{\mathrm{b}}\right)$, the EXAFS
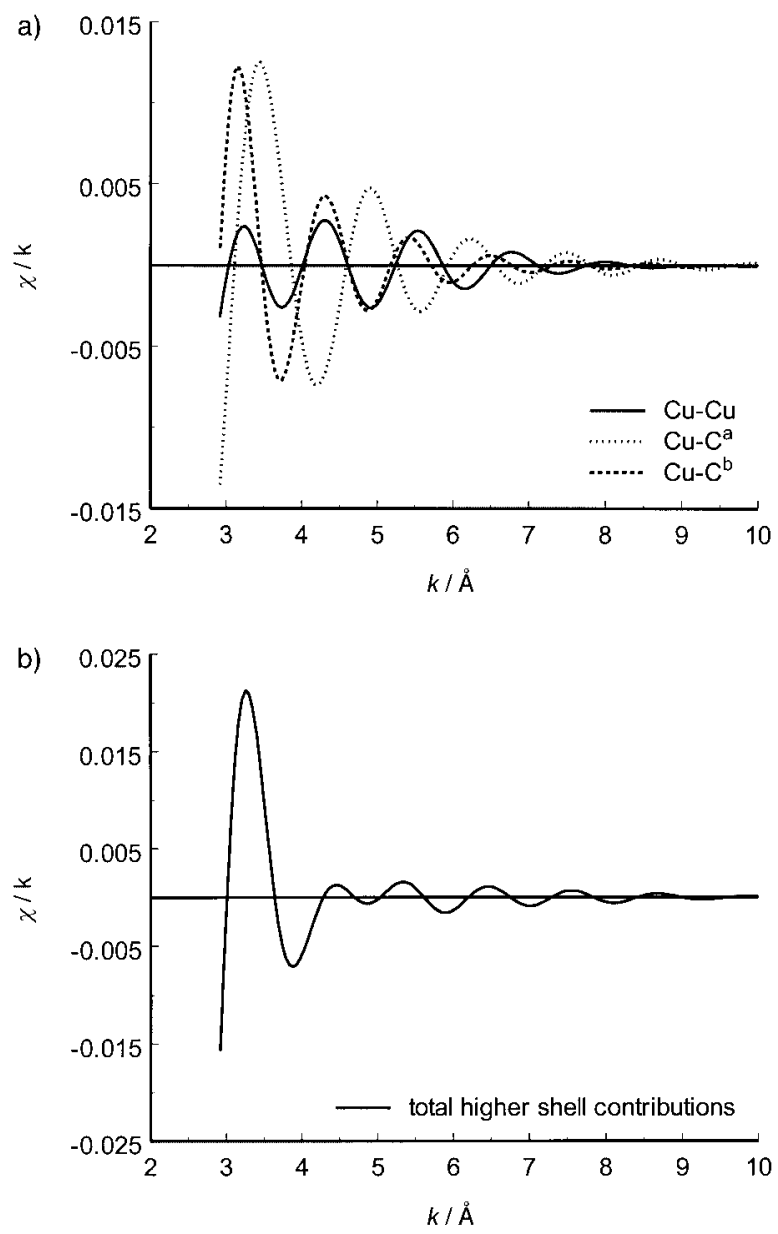

Figure 9. a) Fitted single-shell $\mathrm{Cu}-\mathrm{Cu}, \mathrm{Cu}-\mathrm{C}^{\mathrm{a}}$ and $\mathrm{Cu}-\mathrm{C}^{\mathrm{b}}$ EXAFS contributions of five-shell fit of $\left[\mathrm{Cu}_{3}\left(\mathrm{SAr}^{*}\right)_{3}\right]$ in the solid state; b) total higher shell contributions $\left(\mathrm{Cu}-\mathrm{Cu}+\mathrm{Cu}-\mathrm{C}^{\mathrm{a}}+\mathrm{Cu}-\mathrm{C}^{\mathrm{b}}\right)$ of five-shell fit of $\left[\mathrm{Cu}_{3}\left(\mathrm{SAr}^{*}\right)_{3}\right]$.

analysis leads to a proper $\mathrm{Cu} \cdots \mathrm{Cu}$ distance and structural parameters which correspond to the single-crystal XRD results. In the case of a four-shell fit, the $\mathrm{Cu}-\mathrm{Cu}$ difference file is compensating for the lack of an additional $\mathrm{Cu}-\mathrm{C}$ shell, explaining why an incorrect $\mathrm{Cu} \cdots \mathrm{Cu}$ distance is found in this case. When the Fourier transforms of the $\mathrm{Cu}-\mathrm{Cu}$ and $\mathrm{Cu}-\mathrm{C}^{\text {a }}$ single-shell contributions, displayed here for the $\left[\mathrm{Cu}_{3}(\mathrm{SAr})_{3}\right]$ (solid) in Figure 10, are examined more carefully, the $\mathrm{Cu}-\mathrm{C}^{\text {a }}$ contribution peaks at an even lower distance than the $\mathrm{Cu}-\mathrm{Cu}$ coordination although its distance is larger. This is due to the fact that the position of the peak in the Fourier transform is determined by the argument $(\Phi)$ of the EXAFS function and not solely by $R$, as shown in Equation (5).

$\Phi=2 k R+\phi$

$\phi$ is the phase function of the absorber-backscatterer pair. Although the $\mathrm{Cu}-\mathrm{Cu}$ coordination distance is smaller than for $\mathrm{Cu}-\mathrm{C}^{\mathrm{a}}$, the phase function $(\phi)$ of the $\mathrm{Cu}-\mathrm{C}^{\mathrm{a}}$ is more negative than that of the $\mathrm{Cu}-\mathrm{Cu}$ EXAFS, leading to a $\mathrm{Cu}-\mathrm{C}^{\text {a }}$ peak in the non-phase-corrected Fourier transform at lower values of $R$. This has important consequences in examining the Fourier 

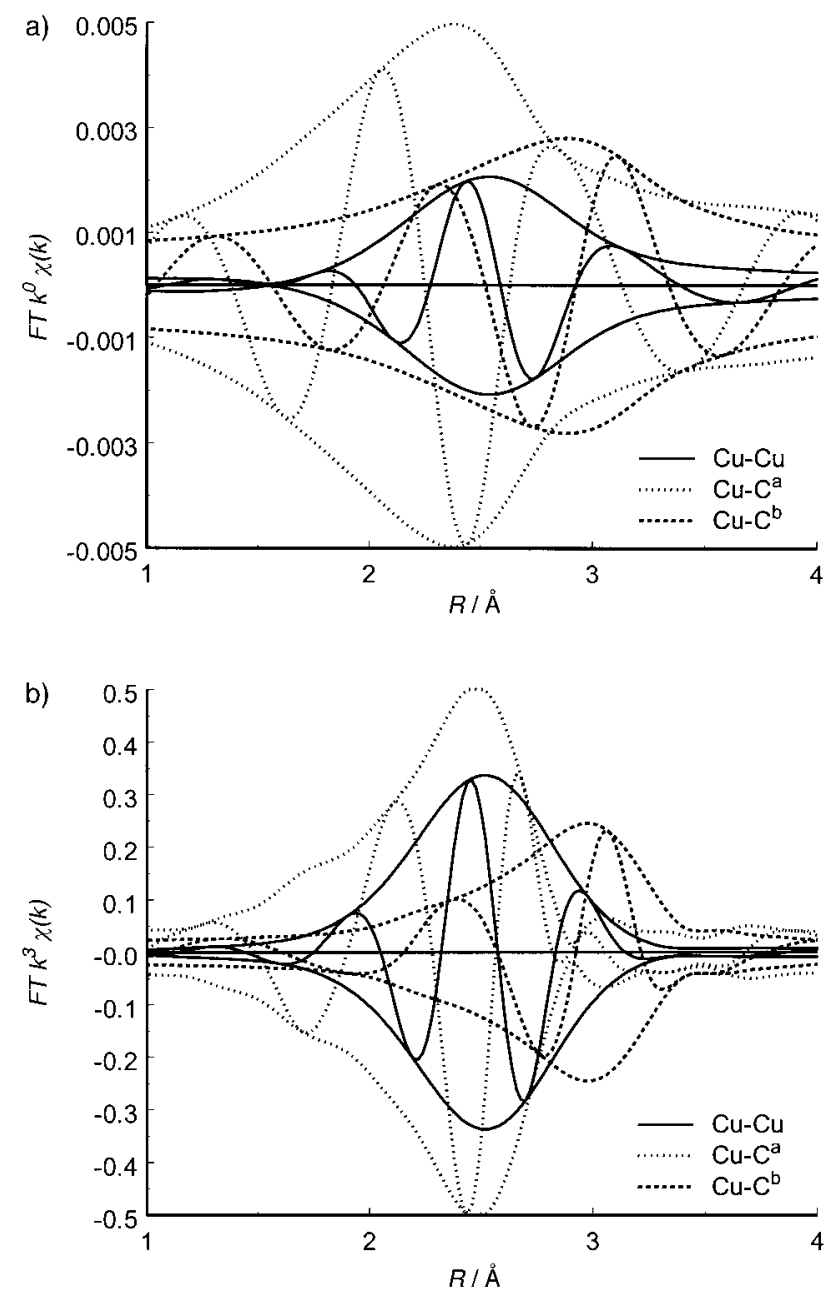

Figure 10. Fourier transform $\left(k^{0}, 2.9<k<12.5 \AA^{-1}\right)$ of fitted single shell $\mathrm{Cu}-\mathrm{Cu}$ (solid line), $\mathrm{Cu}^{-} \mathrm{C}^{\mathrm{a}}$ (dotted line) and $\mathrm{Cu}^{-} \mathrm{C}^{\mathrm{b}}$ (dashed line) contributions of five-shell fit of $\left[\mathrm{Cu}_{3}\left(\mathrm{SAr}^{*}\right)_{3}\right]$ solid state. a) $k^{0}$-weighted; b) $k^{3}$-weighted.

transforms of the difference files for the analysis of the EXAFS data of these classes of $\mathrm{Cu}$ complexes.

In the case of a two-shell fit, all parameters obtained for the $\mathrm{Cu}-\mathrm{N}$ contribution are wrong. The coordination number is twice as high as expected, the distance is $0.1 \AA$ too large and the Debye - Waller factor is unrealistically high. Normally, the first shell in an EXAFS data analysis procedure can be determined with the highest accuracy. However, in this case, the inclusion of higher contributions is required to obtain the correct parameters. Additionally, the $\mathrm{Cu}-\mathrm{S}$ shell can be determined accurately and correctly in all fitting procedures and is not dependent on additional contributions. The explanation for these phenomena consists of two parts: the $\mathrm{Cu}-\mathrm{S}$ shell is the biggest contribution to the total EXAFS spectrum, it has the highest amplitude as can be seen in the Fourier Transforms of the difference files given in Figure $6 \mathrm{a}-\mathrm{e}$. Therefore, the $\mathrm{Cu}-\mathrm{S}$ contribution can be determined with the highest accuracy. Since the $\mathrm{Cu}-\mathrm{S}$ shell is overlapping especially with the $\mathrm{Cu}-\mathrm{N}$ contribution due to their comparable distances, the analysis of this $\mathrm{Cu}-\mathrm{N}$ is more complicated. Moreover, the $\mathrm{Cu}-\mathrm{Cu}$ and $\mathrm{Cu}-\mathrm{C}$ contributions also have a significant amplitude at lower $k$ - and lower $R$-range, causing overlap with the $\mathrm{Cu}-\mathrm{N}$ contribution. A reliable $\mathrm{Cu}-\mathrm{N}$ analysis can thus only be done after inclusion of these higher shells.

To be able to conclude a correct EXAFS analysis the obtained parameters also have to fit correctly using other $k$ weightings. The parameters obtained in the $k^{0}$-weighted fit of the $\left[\mathrm{Cu}_{3}\left(\mathrm{SAr}^{*}\right)_{3}\right](\mathrm{RT})$ have been imported in a $k^{3}$-weighted analysis (as fixed parameters), resulting also in a good fit as can be seen in Figure $5 \mathrm{~b}$ and concluded from the low fit variances as given in Table 4. Moreover, the single shell contributions are also fitted significantly using another $k$ weighting. Therefore, solely based on EXAFS parameters it can be concluded that the data are analysed correctly.

The same observation can be made for the complex in solution, resulting in a good fit in different weightings as can be observed in Figure $7 \mathrm{~b}$ and $\mathrm{c}$ and Table 5. It can be concluded that the resulting parameters give an identical structure to that in the solid state, but with a higher disorder for all contributions.

Using a $k^{3}$-weighted data analysis as normally used in the literature, a good fit but without a $\mathrm{Cu}-\mathrm{Cu}$ contribution is obtained as can be observed in Table 7. The obtained fit

Table 7. EXAFS analysis results of $\left[\mathrm{Cu}_{3}(\mathrm{SAr})_{3}\right], k^{3}$-weighted four-shell fit (without $\mathrm{Cu}-\mathrm{Cu}$ contribution). ${ }^{\text {[a] }}$

\begin{tabular}{llllllll}
\hline $\begin{array}{l}\mathrm{Ab}-\mathrm{Sc} \\
\text { Pair }{ }^{[\mathrm{b}]}\end{array}$ & $N$ & $\begin{array}{l}R \\
{[\AA]}\end{array}$ & $\begin{array}{l}\Delta \sigma^{2} \\
{\left[\AA^{2}\right]}\end{array}$ & $\begin{array}{l}\Delta E_{0} \\
{[\mathrm{eV}]}\end{array}$ & $\begin{array}{l}\text { Var. } \\
\operatorname{Im}^{[\mathrm{b}]}\end{array}$ & $\begin{array}{l}\text { Var. } \\
\text { Abs. }^{[\mathrm{b}]}\end{array}$ \\
\hline $\mathrm{Cu}-\mathrm{N}$ & 1.2 & 2.08 & 0.002 & 0.8 & $k^{0}:$ & 0.42 & 0.08 \\
$\mathrm{Cu}-\mathrm{S}$ & 2.0 & 2.21 & 0.003 & 0.2 & $k^{3}:$ & 0.36 & 0.17 \\
$\mathrm{Cu} \cdots \mathrm{C}^{\mathrm{a}}$ & 2.9 & 2.98 & 0.017 & 8.0 & & & \\
$\mathrm{Cu} \cdots \mathrm{C}^{\mathrm{b}}$ & 3.2 & 3.39 & 0.011 & 1.4 & & &
\end{tabular}

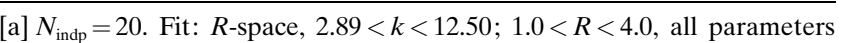
iteratively refined. [b] $\mathrm{Ab}=$ absorber; $\mathrm{Sc}=$ scatterer; Var. Im. and Var. Abs. are the variances of the fit of the Imaginary and Absolute part, respectively.

displays reasonably small variances in both the absolute and the imaginary part of the Fourier transforms in both weightings. Furthermore, the difference files of all contributions are fitted well in this $k^{3}$-weighted Fourier transform. However, if the obtained parameters are imported in a $k^{0}$-weighted fit (as fixed parameters), it can be observed that the higher shell contributions $\left(\mathrm{Cu}-\mathrm{C}^{\mathrm{a}}\right.$ and $\left.\mathrm{Cu}-\mathrm{C}^{\mathrm{b}}\right)$ do not fit well in this weighting. In Figure 11 a the total fit of the $k^{0}$-weighted Fourier transform is displayed, in which for $R>2.2 \AA$ significant differences in absolute and imaginary part can be observed. These differences can be observed more closely by looking at the fits of the difference files of these higher shells $\mathrm{Cu}-\mathrm{C}^{\mathrm{a}}$ and $\mathrm{Cu}-\mathrm{C}^{\mathrm{b}}$ given in Figures $11 \mathrm{~b}$ and c. Clear differences between difference files and single-shell contributions are visible over the whole fitting range, indicating a poor fit for these contributions. Apparently, during fitting, using a single $k^{n}$-weighted analysis, a local minimum can be found which results in a seemingly good analysis without the $\mathrm{Cu}-\mathrm{Cu}$ contribution. This demonstrates the importance of fitting while carefully observing all difference files and total fits in all $k$-weightings.

Anti-phase behaviour can be detected and accounted for by performing a multiple-shell analysis. In order to fit multiple 

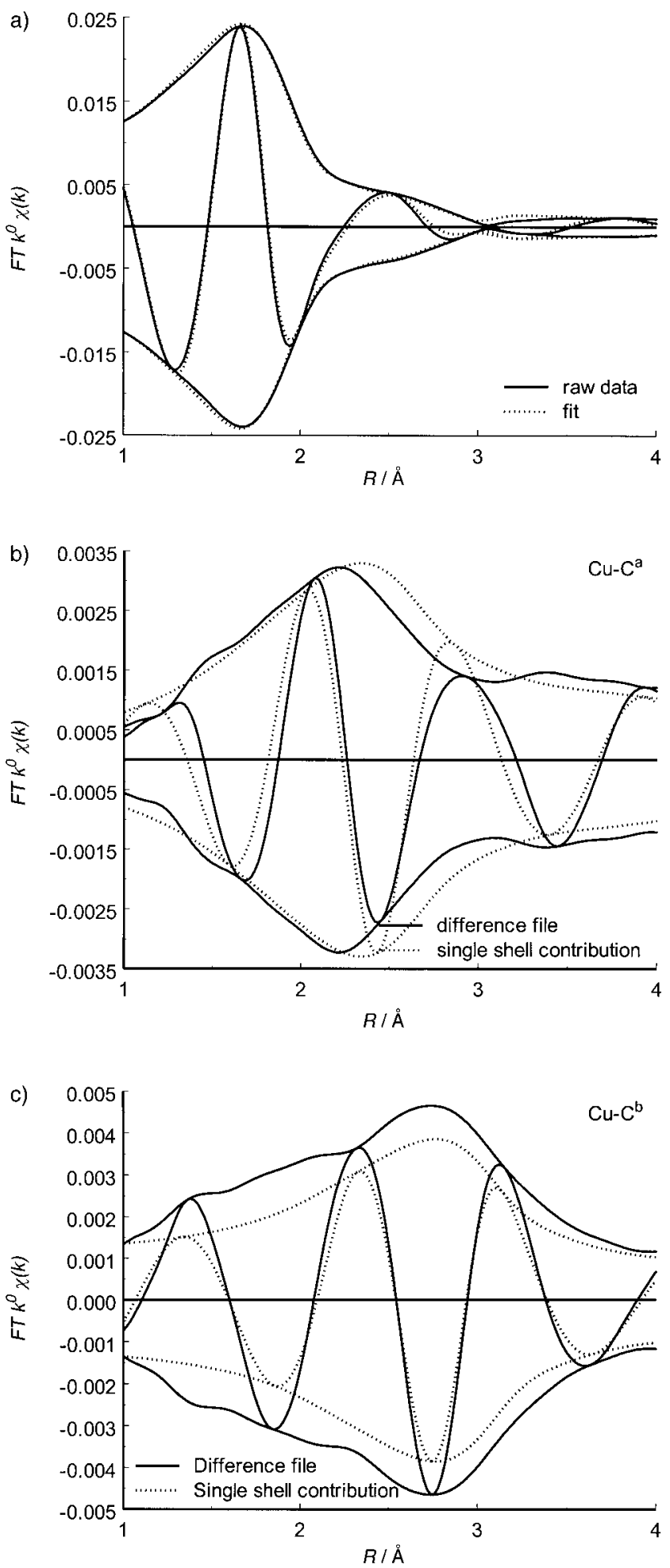

Figure 11. Fourier Transforms of the EXAFS data of $\left[\mathrm{Cu}_{3}\left(\mathrm{SAr}^{*}\right)_{3}\right]$ in the solid state for a single $k^{3}$-weighted fitting procedure $(2.9<k<12.5,1.0<$ $R<4.0$ ) without a $\mathrm{Cu}-\mathrm{Cu}$ contribution, implemented in a $k^{0}$-weighted analysis. a) Total Fourier Transform fit; b) fitted single shell contribution $\mathrm{Cu}-\mathrm{C}^{\mathrm{a}}, \mathrm{c}$ ) fitted single shell contribution $\mathrm{Cu}-\mathrm{C}^{\mathrm{b}}$.

shells the data must be of sufficient quality to allow the required number of data points $\left(N_{\text {ind }}\right)$. Dependending on which contributions are in anti-phase, first or higher shells, the number of independent data points and consequently the quality of the data needed is respectively lower or higher.
EXAFS data-analysis of $\mathrm{Cu}_{4}(\mathrm{SAr})_{2}(\mathrm{Mes})_{2}$ (2) (solid, room temperature): $\mathrm{The} \mathrm{Cu}_{4}(\mathrm{SAr})_{2}(\mathrm{Mes})_{2}(\mathbf{2})$ compound is a mixed organo(arenethiolate)copper(I) aggregate, which contains distinctly different $\mathrm{Cu}$ sites. Different $\mathrm{Cu} \cdots \mathrm{Cu}$ distances are present, making the EXAFS data analysis even more complicated. Figure 8 a displays the Fourier transforms of the EXAFS data using different $k$-weightings. Depending on the $k$-weighting a lack of intensity is observed in different $R$ ranges of the Fourier transforms. This also strongly indicates the presence of anti-phase behaviour of the different EXAFS coordination shells.

The single-shell contributions, as fitted using the difference file technique, show anti-phase behaviour between different shells in different parts of the spectrum. Two clear examples are given in Figures $12 \mathrm{a}$ and b. Figure $12 \mathrm{a}$ shows a contribu-
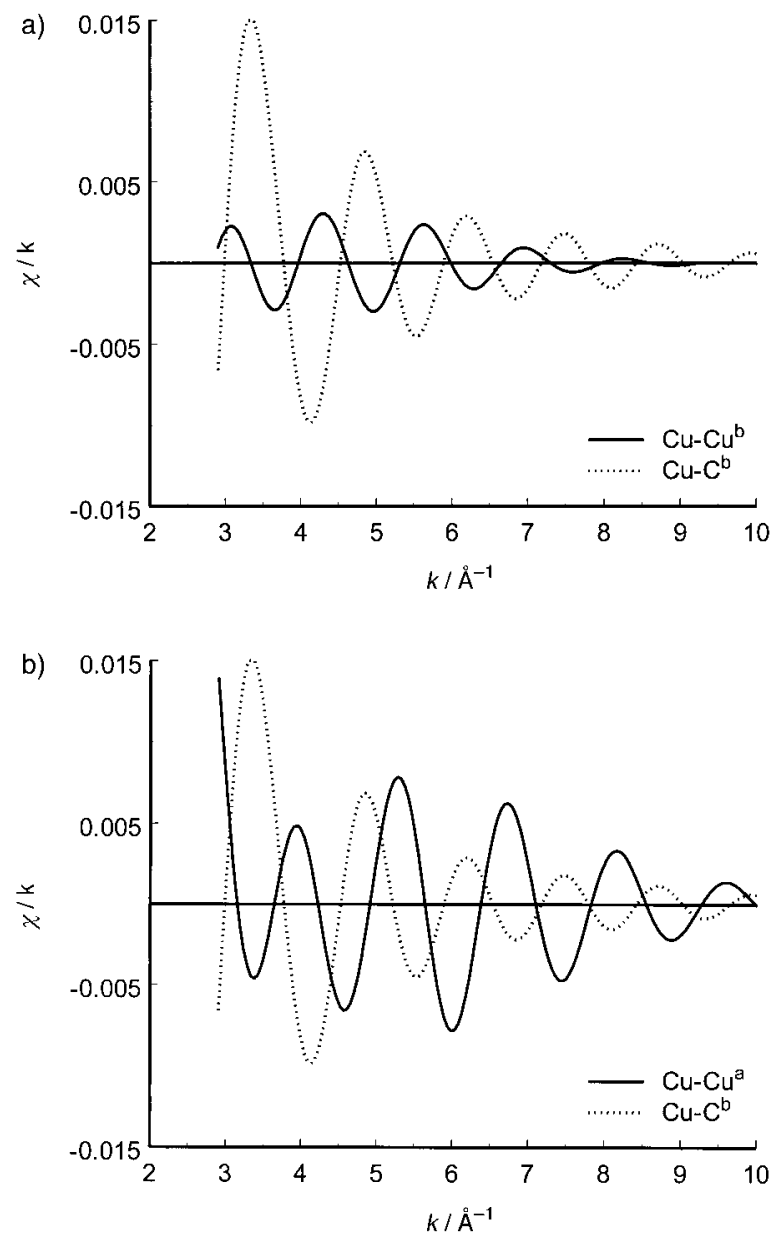

Figure 12. a) Single shell $\mathrm{Cu}-\mathrm{Cu}^{\mathrm{b}}$ and $\mathrm{Cu}-\mathrm{C}^{\mathrm{b}}$ contributions for $\left[\mathrm{Cu}_{4^{-}}\right.$ $\left.(\mathrm{SAr})_{2}(\mathrm{Mes})_{2}\right](2.9<k<12.5,1.0<R<3.0)$; b ) fitted single shell $\mathrm{Cu}-\mathrm{Cu}^{\mathrm{a}}$ and $\mathrm{Cu}-\mathrm{C}^{\mathrm{b}}$ contributions for $\left[\mathrm{Cu}_{4}(\mathrm{SAr})_{2}(\mathrm{Mes})_{2}\right](2.9<k<12.5,1.0<R<$ $3.0)$.

tion with opposite phase for the $\mathrm{Cu}-\mathrm{Cu}^{\mathrm{b}}$ to the $\mathrm{Cu}-\mathrm{C}^{\mathrm{b}}$ contribution in the range of $4.0<k<8.0 \AA^{-1}$. The anti-phase behaviour found for low values of $k$ results in a low intensity in a $k^{0}$-weighted Fourier transform and consequently in a less reliable fit using only a $k^{0}$-weighted analysis. In Figure $12 \mathrm{~b}$ the anti-phase behaviour of the $\mathrm{Cu}-\mathrm{Cu}^{\mathrm{a}}$ and the $\mathrm{Cu}-\mathrm{C}^{\mathrm{b}}$ contributions is displayed. Due to the anti-phase behaviour found at 
higher values of $k$ a small intensity was observed in a $k^{3}$ weighted Fourier transform resulting in a less reliable fit for the $k^{3}$-weighted analysis in this range. A reliable analysis of the data can be performed by dividing the Fourier transform in several regions and fitting these regions with a proper $k$ weighting. The separate difference files, the single-shell fits and the resulting total fit have to be examined in order to detect anti-phase behaviour and to determine the most reliable analysis.

EXAFS data-analysis of copper carbon complexes: detection of $\mathbf{C u}-\mathbf{C u}$ contributions: As described in the introduction, it can be inferred from the literature ${ }^{[25,26,28-35]}$ and confirmed in this study that detection with EXAFS of a $\mathrm{Cu}-\mathrm{Cu}$ contribution in copper-carbon complexes is very difficult. Although a $\mathrm{Cu}-\mathrm{Cu}$ contribution is expected based on other characterisation techniques such as XRD, some authors have been able to analyse their data and to find a good fit without the inclusion of a $\mathrm{Cu}-\mathrm{Cu}$ contribution. ${ }^{[28,30-32,34,35]}$

Many authors are using a $k^{3}$-weighted fit in $k$-space by default, since this type of weighting normally makes the fit sensitive to the presence of high $\mathrm{Z}$ scatterers. If the fit is not checked in a different (low) $k$-weighting an incorrect fit without a $\mathrm{Cu}-\mathrm{Cu}$ contribution can be obtained with low fit variances. $\mathrm{Cu}$ has a maximum in its backscattering amplitude around $k=8 \AA^{-1}$, whereas $\mathrm{C}$ or $\mathrm{N}$ have an amplitude function which rapidly decays with $k$. However, a highly dynamic or structural disorder of the $\mathrm{Cu}-\mathrm{Cu}$ contribution in a $\mathrm{Cu}$ compound will have a detrimental effect on its EXAFS amplitude at high values of $k$. The detection of $\mathrm{Cu}-\mathrm{Cu}$ contributions was already recognised in the literature to be further complicated if additional $\mathrm{Cu}-\mathrm{C}$ shells are present in the same distance range as the $\mathrm{Cu}-\mathrm{Cu}$ contribution. ${ }^{[33]}$ This can be explained by the fact that $\mathrm{Cu}-\mathrm{Cu}$ and $\mathrm{Cu}-\mathrm{C}$ shells can have opposite phase. When anti-phase behaviour is observed, especially at higher $k$-weightings, a single $k^{3}$-weighted analysis will not be sensitive for these higher shells. Only if anti-phase behaviour is observed at low $k$-ranges or if no anti-phase behaviour is observed at all, a single $k^{3}$-weighted fit results in a reliable analysis of the EXAFS data. In addition to the application of the appropriate weighting(s), it is demonstrated in this paper that $R$-space fitting while using the difference file technique enables a careful examination of the different contributions, both individually and relative to each other. This can lead to the unravelling of anti-phase behaviour and therefore to a reliable analysis of the EXAFS data.

The structure as a function of the state of aggregation: The structure of $\left[\mathrm{Cu}_{3}\left(\mathrm{SAr}^{*}\right)_{3}\right]$ contains a $\mathrm{Cu}_{3} \mathrm{~S}_{3}$ six-membered ring in a chair-like conformation with alternating copper and sulfur atoms. The $\mathrm{C}_{6} \mathrm{H}_{3}\left((R)-\mathrm{CH}(\mathrm{Me}) \mathrm{NMe}_{2}\right)-2$ group is bonded on each sulphur atom equatorially with respect to this ring. The bonding behaviour of the $\mathrm{Cu}-\mathrm{S}-\mathrm{Cu}$ bridge in the $\mathrm{Cu}_{3} \mathrm{~S}_{3}$ ring is discussed extensively in several places. ${ }^{[14,21]}$ It is clear that the complex is still present as a trimer in solution and that the structure is in fact identical to that in the solid state. The dynamics of the vibrating ring adds an additional contribution to the Debye-Waller factor, which is comparable for all interactions. This indicates that dissolving the complex only influences its vibrational behaviour and no preferable vibrations or vibration direction of the ring can be observed.

The results discussed above make clear that only after understanding how $\mathrm{Cu}$ K-edge EXAFS in organocopper samples should be analysed, structural information about these complexes in both solids and in solution can be obtained. It has been shown that different states of aggregation give additional information about the dynamics of the $\mathrm{Cu}$ arenethiolate complexes. The technique has proven its strengths and possibilities and can now be used for the determination of reaction intermediates in the $\mathrm{C}-\mathrm{C}$ bond formation reactions mentioned earlier.

\section{Conclusion}

With a systematic analysis of the $\mathrm{Cu}$ K-edge EXAFS data, XAFS spectroscopy is a very good tool for the investigation of $\mathrm{Cu}$ complexes, both in the solid phase and in solution. The obtained EXAFS data have to be analysed very carefully, especially by looking at the influence of different $k$-weightings, as using a single $k$-weighting may lead to false minima in variances. When, during $R$-space fitting, the difference file technique is applied, the different individual contributions to the total EXAFS spectrum can be examined in detail which helps to detect and unravel anti-phase behaviour of different contributions. When all contributions are statistically relevant (well above the noise level) and the total fit as well as all individual contributions fit the obtained EXAFS data very well in all different $k$-weightings, a good and reliable analysis can be concluded. This analysis procedure is solely based on EXAFS parameters making it applicable to every (non- $\mathrm{Cu}$ ) EXAFS spectrum obtained.

In this study it is shown that $\mathrm{Cu}$ K-edge EXAFS spectroscopy can provide detailed information about the homogeneous catalysts in reaction media and can now be used to give insights in the reactivity of homogeneous complexes and their way to form catalytic intermediates in the presence of the Grignard reagents and substrates.

\section{Experimental Section}

All experiments were carried out using standard Schlenk techniques under an inert oxygen-free nitrogen atmosphere using flame-dried glassware. The samples were sealed in the EXAFS probe in a Faircrest glove-box equipped with $\mathrm{O}_{2}$ and $\mathrm{H}_{2} \mathrm{O}$ indicators, operating on 3 inch nitrogen over-pressure. Boron nitride $(99 \%)$ and anhydrous toluene $(99+\%)$ were purchased from Aldrich Chemical Co., UK. $\left[\mathrm{Cu}_{3}\left\{\mathrm{SC}_{6} \mathrm{H}_{4}\left((R)-\mathrm{CH}(\mathrm{Me}) \mathrm{NMe}_{2}\right)-2\right\}_{3}\right]$ $(\mathbf{1})^{[14]},\left[\mathrm{Cu}_{4}(\mathrm{SAr})_{2}(\mathrm{Mes})_{2}\right](\mathbf{2})^{[21]}$ were prepared according to literature methods.

EXAFS data collection: $\mathrm{Cu}$ K-edge $(8979.0 \mathrm{eV})$ EXAFS spectra were measured at the Synchrotron Radiation Source (SRS) in Daresbury, United Kingdom, Station 8.1, using a $\mathrm{Si}(220)$ double crystal monochromator and at the European Synchrotron Radiation Facility (ESRF) in Grenoble, France, Beamline 29, using a $\mathrm{Si}(111)$ double crystal monochromator. The monochromator was detuned to $50 \%$ intensity to avoid effects of higher harmonics present in the X-ray beam. The measurements were done in the transmission mode using optimised ion chambers as detectors. To decrease noise, scans were made in $k$-space and three scans were collected for each sample. 
Sample preparation in the solid state: Solid material and a known amount of boron nitride were thoroughly mixed and pressed into a self-supporting wafer (calculated to have a maximum total absorbance of 2.5 with a preferable step-size of 1) and placed in an air- and water-tight EXAFS cell provided with X-ray transparent beryllium windows. ${ }^{[42]}$

\section{Sample details}

$\left[\mathbf{C u}_{3}\left(\mathbf{S A r}^{*}\right)_{3}\right]$ (1), solid: A self-supporting wafer was pressed from $35.5 \mathrm{mg} \mathbf{1}$ and boron nitride $(50 \mathrm{mg})$.

[C $\left.\mathbf{C u}_{3}\left(\mathbf{S A r}^{*}\right)_{3}\right]$ (1) in solution: $\left[\mathrm{Cu}_{3}\left(\mathrm{SAr}^{*}\right)_{3}\right](33.4 \mathrm{mg}, 0.0457 \mathrm{mmol})$ was dissolved in toluene $(1.1 \mathrm{~mL})$ and this solution was transferred into the EXAFS liquid cell making sure that the cell was completely filled.

[C $\left.\mathbf{C u}_{4}(\mathbf{S A r})_{2}(\mathbf{M e s})_{2}\right]$ (2), solid: A wafer was pressed from $9 \mathrm{mg} \mathbf{2}$ and boron nitride $(63 \mathrm{mg})$.

\section{Acknowledgement}

We acknowledge the CLRC Daresbury Laboratory for the provision of synchrotron radiation. We acknowledge the European Synchrotron Radiation Facility for provision of synchrotron radiation facilities and we would like to thank M. Borowski for assistance in using beamline BM29. The NRSC-Catalysis is gratefully acknowledged for financial support.

[1] H. Hope, M. M. Olmstead, P. P. Power, J. Sandell, X. Xu, J. Am. Chem. Soc. 1985, 107, 4337.

[2] P. Leoni, M. Pasquali, C. A. Ghilardi, J. Chem. Soc. Chem. Commun. 1983, 240.

[3] G. van Koten, J. G. Noltes, J. Am. Chem. Soc. 1979, 101, 6593.

[4] G. Boche, F. Bosold, H. Marsch, K. Harms, Angew. Chem. 1998, 110, 1779; Angew. Chem. Int. Ed. 1998, 37, 1684.

[5] C-S. Hwang, P. P. Power, J. Am. Chem. Soc. 1998, 120, 6409.

[6] C. M. P. Kronenburg, J. T. B. H. Jastrzebski, A. L. Spek, G. van Koten, J. Am. Chem. Soc. 1998, 120, 9688

[7] B. H. Lipshutz, R. S. Wilhelm, J. Am. Chem. Soc. 1981, 103, 7672.

[8] G. H. Posner, An introduction to Synthesis Using Organocopper Reagents, Wiley, New York, 1980.

[9] B. H. Lipshutz, S. Sengupta, Org. React. 1992, 41, 139

[10] B. H. Lipshutz, R. S. Wilhelm, J. A. Kozlowski, Tetrahedron 1984, 40, 5005 .

[11] S. H. Bertz, E. H. Fairchild, Encyclopedia of Reagents for Organic Synthesis, Wiley, New York, 1995, pp. 1312-1315, 1341-1343, $1346-$ 1349.

[12] N. Krause, A. Gerold, Angew. Chem. 1997, 109, 194; Angew. Chem. Int. Ed. Engl. 1997, 36, 186.

[13] D. M. Knotter, G. van Koten, H. L. van Maanen, D. M. Grove, A. L. Spek, Angew. Chem. 1989, 101,351; Angew. Chem. Int. Ed. Engl. 1989, 28,341 .

[14] D. M. Knotter, H. L. van Maanen, D. M. Grove, A. L. Spek, G. van Koten, Inorg. Chem. 1991, 30, 3309.

[15] M. D. Janssen, D. M. Grove, G. van Koten, Progr. Inorg. Chem. 1997, $46,97$.
[16] M. van Klaveren, F. Lambert, D. J. F. M. Eijkelkamp, D. M. Grove, G. van Koten, Tetrahedron Lett. 1994, 35, 6135.

[17] A. Haubrich, M. van Klaveren, G. van Koten, G. Handke, N. Krause, J. Org. Chem. 1993, 58, 5849.

[18] M. van Klaveren, E. S. M. Persson, D. M. Grove, J. E. Bäckvall, G. van Koten, Tetrahedron Lett. 1994, 35, 5931.

[19] G. van Koten, J. Organomet. Chem. 1990, 400, 283.

[20] F. Lambert, D. M. Knotter, M. D. Janssen, M. van Klaveren, J. Boersma, G. van Koten, Tetrahedron Asymm. 1991, 2, 1097.

[21] D. M. Knotter, D. M. Grove, W. J. J. Smeets, A. L. Spek, G. van Koten, J. Am. Chem. Soc. 1992, 114, 3400.

[22] G. van Koten, J. Organomet. Chem. 1990, 400, 483.

[23] G. van Koten, Pure and Appl. Chem. 1994, 66(7), 1455.

[24] Q. Zhou, A. Pfaltz, Tetrahedron Lett. 1993, 34, 7725.

[25] G. Henkel, A. Müller, S. Weissgräber, G. Buse, T. Soulimane, G. C. M. Steffens, H.-F. Nolting, Angew. Chem. 1995, 107, 847; Angew. Chem. Int. Ed. Engl. 1995, 34, 1488.

[26] H. Bertagnolli, W. Kaim, Angew. Chem. 1995, 107, 847; Angew. Chem. Int. Ed. Engl. 1995, 34, 771.

[27] D. C. Koningsberger, R. Prins, X-ray Absorption: Principles, Applications, Techniques of EXAFS, SEXAFS and XANES, Wiley, New York, 1988.

[28] H. Huang, C. H. Liang, J. E. Penner-Hahn, Angew. Chem. 1998, 110, 1628; Angew. Chem. Int. Ed. 1998, 37, 1564.

[29] J. H. Bitter, B. L. Mojet, M. D. Janssen, D. M. Grove, G. van Koten, D. C. Koningsberger, J. Synchrotron Rad. 1999, 6, 423.

[30] T. M. Barnhart, J. E. Penner-Hahn, Physica B 1995, 208\&209, 709.

[31] T. Stemmler, J. E. Penner-Hahn, P. Knochel, J. Am. Chem. Soc. 1993, 115,348 .

[32] T. Stemmler, T. M. Barnhart, J. E. Penner-Hahn, C. E. Tucker, P. Knochel, H. Böhme, G. Frenking, J. Am. Chem. Soc. 1995, 117, 12489.

[33] R. A. Scott, M. K. Eidsness, Comments Inorg. Chem. 1988, 7(5), 235, and references therein.

[34] N. J. Blackburn, R. W. Strange, R. W. Cruse, K. D. Karlin, J. Am. Chem. Soc. 1987, 109, 1235.

[35] I. Persson, J. E. Penner-Hahn, K. O. Hodgson, Inorg. Chem. 1993, 32, 2497.

[36] A. L. Ankudinov, B. Ravle, J. J. Rehr, S. D. Conradson, Phys. Rev. B. 1998, 7565.

[37] A. Lommen, K. I. Pandya, D. C. Koningsberger, G. W. Canters, Biochim. Biophys. Acta 1991, 1076, 439.

[38] M. Vaarkamp, J. C. Linders, D. C. Koningsberger, Physica B. 1995 , $208 \& 209,159$

[39] D. C. Koningsberger, B. L. Mojet, G. E. van Dorssen, D. E. Ramaker, Top. Catal. 2000, 10, 143.

[40] D. C. Koningsberger, Jpn. J. Appl. Phys. 1993, 32 suppl. $32-2,877$.

[41] J. B. A. D. van Zon, D. C. Koningsberger, H. F. J. van Blik, D. E. Sayers, J. Chem, Phys. 1985, 82, 5742.

[42] F. W. H. Kampers, T. M. J. Maas, J. van Grondelle, P. Brinkgreve, D. C Koningsberger, Rev. Sci. Instrum. 1989, 60, 2635.

Received: January 4, 2002 Revised: August 12, 2002 [F3778] 